\title{
Neurogenesis in the nematode Caenorhabditis elegans
}

\author{
Oliver Hobert ${ }^{\S}$, Department of Biochemistry \& Molecular Biophysics, \\ Howard Hughes Medical Institute, Columbia University Medical Center, \\ New York, NY
}

\section{Table of Contents}

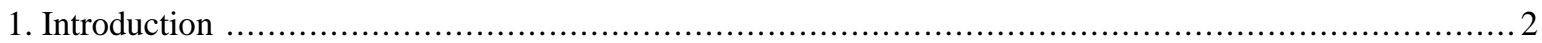

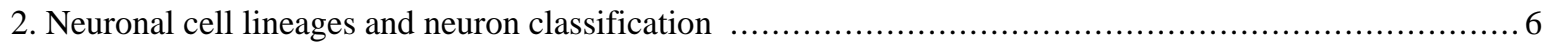

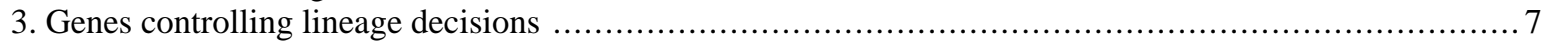

3.1. Neuronal vs. non-neuronal lineage transformations .......................................... 7

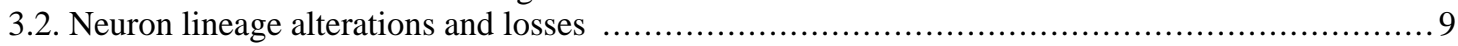

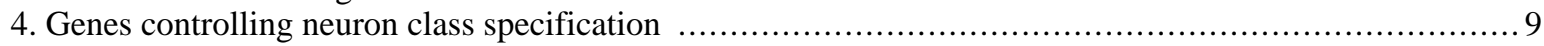

4.1. Terminal selectors control terminal neuron identity .......................................... 10

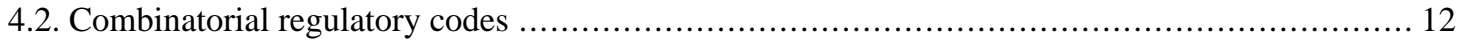

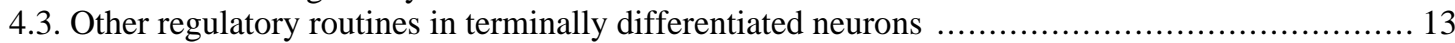

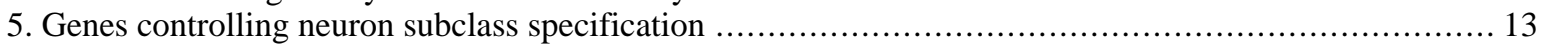

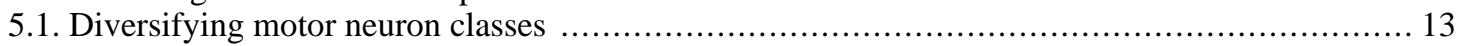

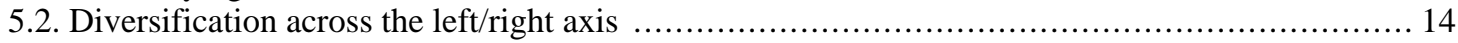

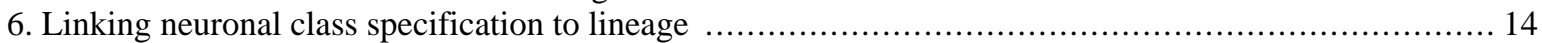

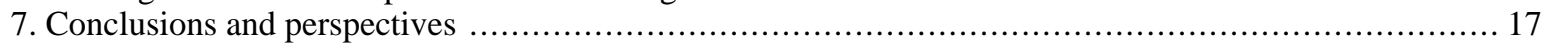

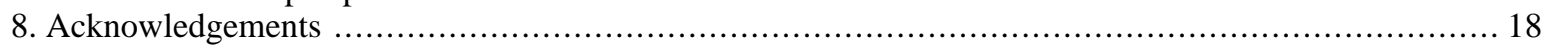

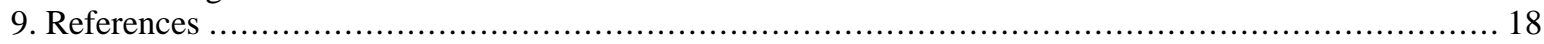

\begin{abstract}
The nervous system represents the most complex tissue of $C$. elegans both in terms of numbers (302 neurons and 56 glial cells $=37 \%$ of the somatic cells in a hermaphrodite) and diversity (118 morphologically distinct neuron classes). The lineage and morphology of each neuron type has been described in detail and neuronal fate markers exists for virtually all neurons in the form of fluorescent reporter genes. The ability to "phenotype" neurons at high resolution combined with the amenability of $C$. elegans to genetic mutant analysis make the $C$. elegans nervous system a prime model system to elucidate the nature of the gene regulatory programs that build a nervous system-a central question of developmental neurobiology. Discussing a number of regulatory genes involved in neuronal
\end{abstract}

\footnotetext{
*Edited by Erik M. Jorgensen and Joshua M. Kaplan. Last revised June 24, 2010. Published October 4, 2010. This chapter should be cited as: Hobert O. Neurogenesis in the nematode Caenorhabditis elegans (October 4, 2010), WormBook, ed. The C. elegans Research Community, WormBook, doi/10.1895/wormbook.1.12.2, http://www.wormbook.org.

Copyright: () 2010 Oliver Hobert. This is an open-access article distributed under the terms of the Creative Commons Attribution License, which permits unrestricted use, distribution, and reproduction in any medium, provided the original author and source are credited.

${ }^{\S}$ To whom correspondence should be addressed. E-mail: or38@columbia.edu
} 
lineage determination and neuronal differentiation, I will try to carve out in this review a few general principles of neuronal development in C. elegans. These principles may be conserved across phylogeny.

\section{Introduction}

The nervous system of the C. elegans hermaphrodite is composed of 302 neurons that are organized in several ganglia in the head and tail and into a spinal cord-like ventral nerve cord (Figure 1A) (White et al., 1986) (a detailed description of the anatomy of the nervous system can be found at WormAtlas). Even though many C. elegans neurons look simple at a gross anatomical level, most $C$. elegans neurons are sophisticated information processing devices that show complex patterns of wiring to other neurons (White et al., 1986) (Figure 1B), and often co-express an astounding number of signaling molecules, i.e. neurotransmitters and their receptors (see expression pattern descriptions at WormBase). For example, transcriptome studies have shown that a single sensory neuron expresses 14 different neurotransmitter receptors (ionotropic or metabotropic) and 10 neuropeptides (Etchberger et al., 2007). The nervous system of $C$. elegans processes a variety of distinct sensory modalities (some shown in Figure 1B), integrates them, and generates distinct patterns of behavioral outputs (de Bono and Maricq, 2005; Hobert, 2003). Information processing in the nervous system involves various forms of associative and non-associative learning processes. Complex in function and diverse in cell types, the $C$. elegans nervous system represents a useful model to ask how a nervous system develops. The key advantages of the system that one can bring to bear on this question and that set $C$. elegans apart from other model systems are several fold. First, the genetic amenability of the worm has allowed the retrieval of a large number of mutants required for the specification of cells within the nervous system (Table 1). Second, the exquisitely well-described anatomy, lineage, and molecular composition of individual neurons allows one to assess in detail the impact of gene removal on those parameters. Third, the ease with which reporter gene constructs can be generated has shed light on the cis-regulatory logic of neuronal specification. I will describe here some of these points in more detail, but will first start with a brief recap of the key blueprint of the nervous system-its lineage diagram - elucidated by John Sulston and colleagues almost 30 years ago (Figure 2) (Sulston, 1983; Sulston et al., 1980; Sulston and Horvitz, 1977; Sulston et al., 1983). The reader is also referred to a previous version of this chapter (Specification of the nervous system) on which I expand here.

Table 1. Genes controlling neuronal specification in C. elegans

\begin{tabular}{|l|l|l|}
\hline Gene name & Gene class & Function \\
\hline Gene regulatory factors & \multicolumn{2}{|l|}{} \\
\hline ahr-1 & Zn finger & $\begin{array}{l}\text { regulates alternative differentiation program (d/v vs. 1/r RME) } \\
\text { axon pathfinding/migration (AVM, SDQ) }\end{array}$ \\
\hline alr-1 & homeobox & $\begin{array}{l}\text { neuroblast identity } \\
\text { regulates alternative differentiation program (VD vs. DD) }\end{array}$ \\
\hline ast-1 & ETS & $\begin{array}{l}\text { terminal selector (dopaminergic neurons) } \\
\text { axon pathfinding (command interneurons) }\end{array}$ \\
\hline ceh-10 & Prd-type homeobox & terminal selector (AIY, possibly CAN) \\
\hline ceh-12 & homeobox & motor neuron class specification \\
\hline ceh-14 & LIM homeobox & $\begin{array}{l}\bullet \\
\text { putative terminal selector (ALA) }\end{array}$ \\
\hline subaspects of differentiation (AFD)
\end{tabular}


Neurogenesis in the nematode Caenorhabditis elegans

\begin{tabular}{|c|c|c|}
\hline Gene name & Gene class & Function \\
\hline cnd-1 & bHLH & neuroblast identity \\
\hline $\operatorname{cog}-1$ & homeobox & subtype identity switch (ASEL vs. ASER) \\
\hline daf-19 & RFX-type & terminal selector for sensory neuron ciliogenesis \\
\hline die-1 & Zn finger & subtype identity switch (ASEL vs. ASER) \\
\hline egl-43 & Zn finger & neuron migration \\
\hline egl-44 & TEF domain & $\begin{array}{ll}- & \text { represses alternative fate (FLP) } \\
\text { - } & \text { candidate terminal selector (HOB) } \\
\text { - } & \text { neuron migration/pathfinding (HSN) }\end{array}$ \\
\hline egl-46 & Zn finger & 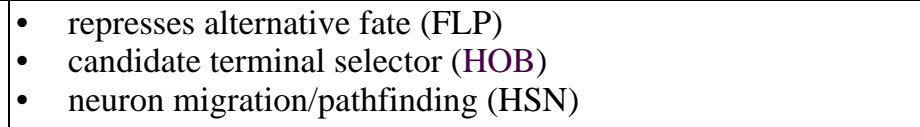 \\
\hline egl-5 & HOX cluster gene & $\begin{array}{l}\text { - } \text { male sensory neuron identity } \\
\text { - aspects of neuronal differentiation (HSN axon pathfinding) }\end{array}$ \\
\hline fax-1 & $\begin{array}{l}\text { Orphan nuclear } \\
\text { receptor }\end{array}$ & aspects of neuronal differentiation (command interneurons) \\
\hline$f k h-2$ & forkhead & ciliogenesis \\
\hline fozi-1 & Zn finger & subtype identity switch (ASEL vs. ASER) \\
\hline ham-2 & Zn finger & neuron migration \\
\hline hif-1 & bHLH-PAS & modulates neuron function (ASG) \\
\hline hlh-14 & bHLH & proneural \\
\hline hlh-17 & bHLH & glia cell differentation \\
\hline hlh-3 & bHLH & axon pathfinding (HSN) \\
\hline $\lim -4$ & LIM homeobox & - $\quad$ putative terminal selector (AWB) \\
\hline lim-6 & LIM homeobox & $\begin{array}{l}\text { - } \quad \text { specifying some aspects of GABAergic neuron specification } \\
\text { - subtype identity switch (ASEL vs. ASER) }\end{array}$ \\
\hline lin-4 & miRNA & - timing of neuroblast divisions \\
\hline $\operatorname{lin}-11$ & LIM homeobox & $\begin{array}{ll}- & \text { terminal selector (AVG) } \\
- & \text { transient inducer of terminal selector? (AWA) } \\
\text { - } & \text { axon pathfinding (VC motor neurons) }\end{array}$ \\
\hline $\operatorname{lin}-14$ & $\begin{array}{l}\text { novel DNA binding } \\
\text { protein }\end{array}$ & $\begin{array}{l}\text { - timing of neuroblast divisions } \\
\text { - } \quad \text { synaptic rewiring }\end{array}$ \\
\hline $\operatorname{lin}-32$ & bHLH & proneural \\
\hline lin-39 & HOX cluster gene & neuroblast identity \\
\hline lsy-6 & miRNA & - $\quad$ subtype identity switch (ASEL vs. ASER) \\
\hline$m a b-18$ & Pax gene & male sensory neuron identity \\
\hline$m a b-3$ & DM domain & neuroblast identity \\
\hline$m a b-5$ & HOX cluster gene & neuroblast migration, neuroblast identity \\
\hline$m b r-1$ & HTH & axon morphology (AIM neurons) \\
\hline$m e c-3$ & LIM homeobox & $\begin{array}{l}\text { - } \quad \text { terminal selector (touch neurons) } \\
\text { - } \quad \text { dendritic branching (PVD) }\end{array}$ \\
\hline$m l s-2$ & homeobox & $\begin{array}{l}\text { - transient inducer of terminal selector? (AWC) } \\
\text { - glia cell differentation }\end{array}$ \\
\hline$m n m-2$ & Zn finger & axon path finding (pharyngeal motor neurons) \\
\hline
\end{tabular}




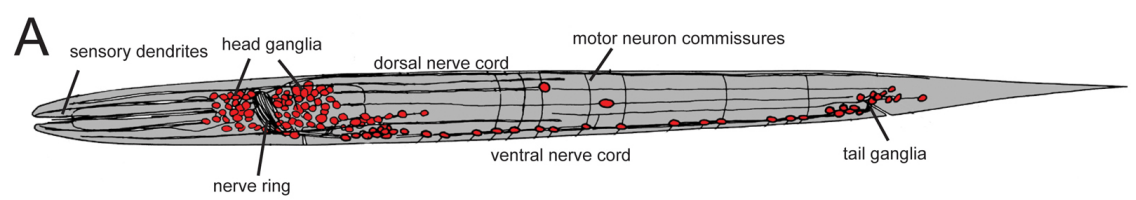

B
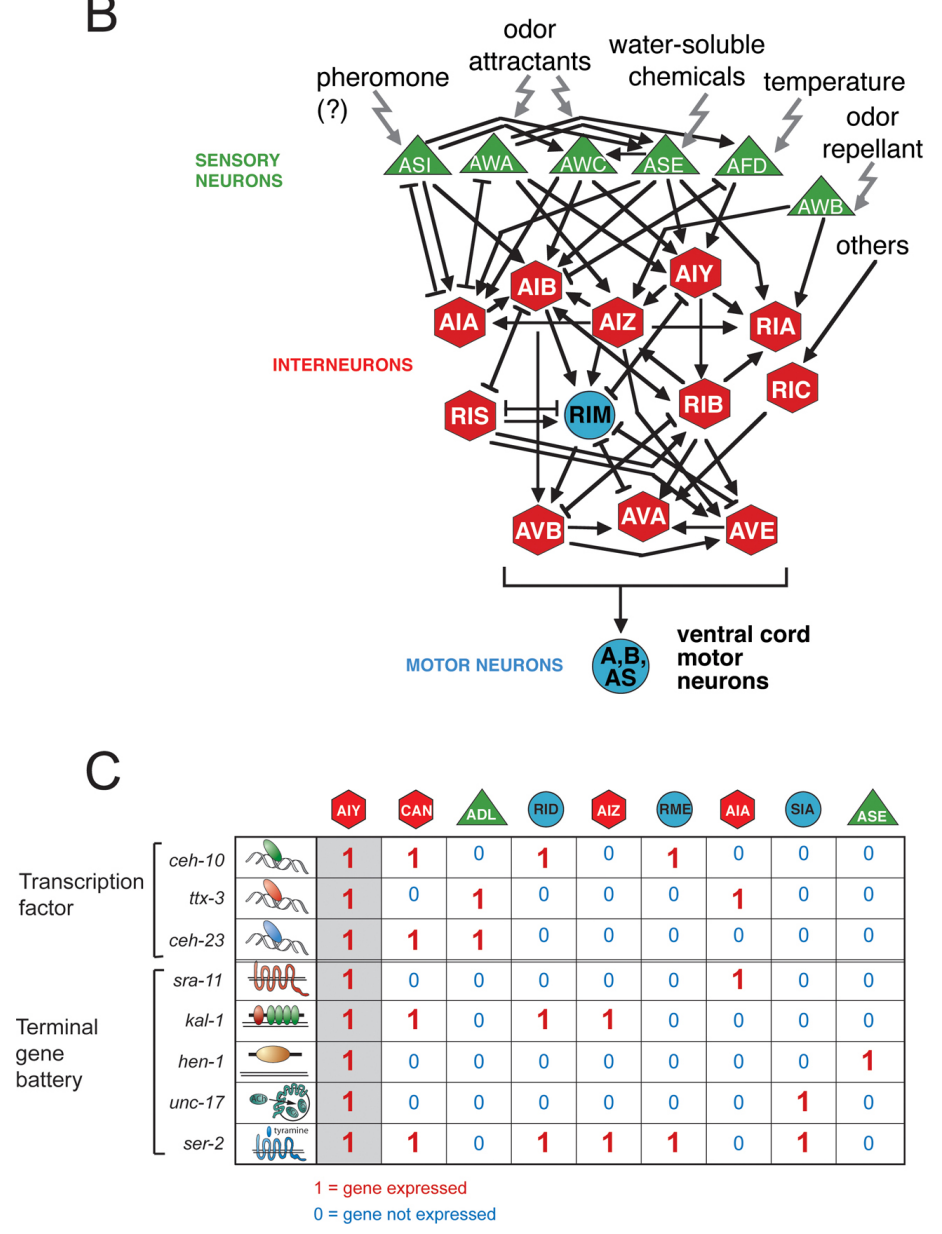

Figure 1. An exemplary view of some structural and molecular features of the $C$. elegans nervous system.

(A) Overall organization of the C. elegans nervous system (White et al., 1986). Neurons are in red. In the first larval stage, shown here schematically, there are 222 neurons (202 somatic, 20 pharyngeal). During larval development a number of neurons are added resulting in a total number of 302 neurons in the adult hermaphrodite and 383 in the adult male (most of the male specific neurons are in the tail). For a more detailed description of the anatomy, see WormAtlas.

(B) Individual neuron types are highly connected information processing devices (White et al., 1986). Some of the circuitry processing various sensory modalities is shown (adapted from Tsalik and Hobert, 2003), reviewed in de Bono and Maricq (2005) and Hobert (2003). Arrows indicate chemical synapses, bars indicate electrical synapses, according to White et al. (1986).

(C) Combinatorial gene expression patterns are unique identifiers of terminal neuron fates. Individual neuron types, exemplified here with the AIY interneuron class, are defined not by the expression of unique terminal differentiation genes, but by the expression of a unique combination of more broadly expressed genes (shown here is only a small selection: the GPCR sra-11, the secreted ligand hen-1, the matrix protein kal-1 and the vesicular acetylcholine transporter unc-17; not all cells expressing these genes are shown) (Altun-Gultekin et al., 2001). This holds both for "terminal differentiation genes", i.e. genes coding for nuts-and-bolts proteins that define the property of a neuron (neurotransmitter receptors, signaling molecules etc.), and also usually for transcription factors that act combinatorially to define the respective individual neuron classes. Neuron type specification therefore involves hierarchical levels of combinatorial codes of co-expressed genes. The binary "on"/"off" behavior of gene expression is likely an oversimplification since intermediary, differential levels of gene expression may also be instructive (for example, the cut gene in Drosophila (Grueber et al., 2003)). Adapted from Wenick and Hobert (2004). 


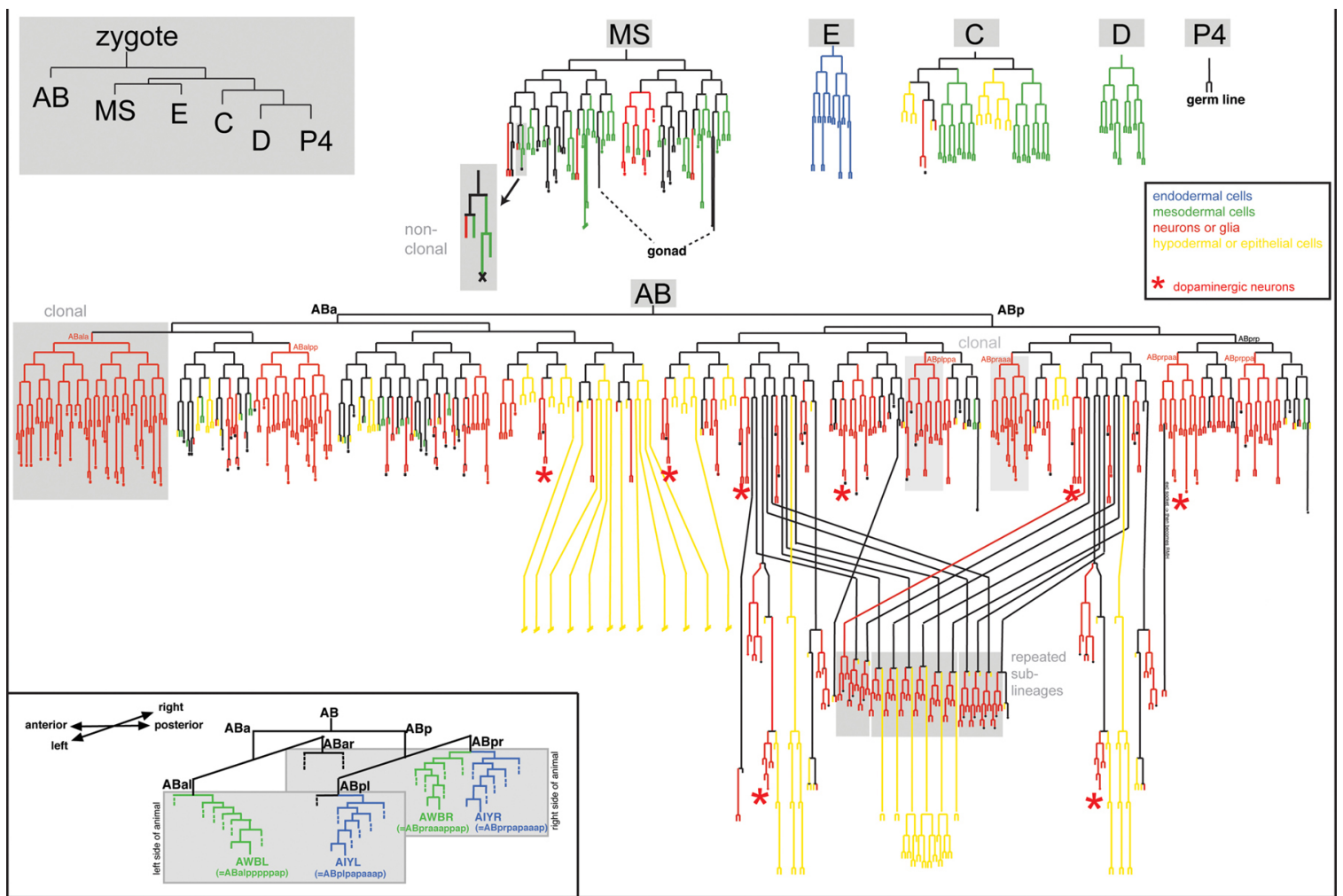

Figure 2. The complete lineage of the C. elegans nervous system. The upper left panel indicates embryonic blastomeres. All other lineages are descendants of these blastomeres. Strike-through indicates that the lineage has not been drawn out to completion. A few specific features are highlighted in grey boxes and with red stars (dopaminergic neurons, to illustrate the lineage diversity of neurons sharing a neurotransmitter). The inset shows two examples of two bilaterally symmetric neuron pairs, one of which has a left/right symmetric lineage (AIYL and AIYR), the other having no obvious lineage relationship (AWBL and AWBR). Adapted and modified from Sulston et al. (1983).

\section{Neuronal cell lineages and neuron classification}

Sulston's lineage diagram reveals some key features of nervous system development (Figure 2). As a quick glance at the diagram shows, $C$. elegans neurons are largely non-clonally derived from many different lineages (red lines in Figure 2). Some lineage sub-branches give rise exclusively to neurons, yet in some cases neuronal vs. non-neuronal choices are made only very late in the lineage (a few examples are shaded in grey in Figure 2). For example, some muscle cells are produced within lineages that mainly produce neurons and vice versa (Sulston et al., 1983) (Figure 2). This indicates that precursor cells in such lineages remain uncommitted to a specific fate until the terminal cell division. Alternatively, cells may be committed but commitment may not be an irreversible process. Consistent with the latter view, one cell in C. elegans undergoes a process of postmitotic "transdifferentiation" from a non-neuronal to a neuronal cell type (Jarriault et al., 2008).

The non-clonal, "piece-meal" nature of neuronal lineages is paralleled by a lack of correlation of lineage history with specific terminal features of neuron types. For example, embryonically generated ventral nerve cord motor neurons that fall into specific anatomic classes (e.g., the nine DA neurons DA1-DA9) show little lineage relation to one another; similarly, amphid sensory neurons involved in detecting environmental cues derive from distinct lineage branches (Sulston et al., 1983). Another broadly applied classification of neurons is based on the type of neurotransmitter that a neuron produces ("neurotransmitter phenotype"). However, C. elegans neurons with the same neurotransmitter phenotype show little if any lineage relation (Sulston, 1983) (Figure 2 shows as an example the lineal position of the 8 dopaminergic neurons of a C. elegans hermaphrodite). Another classification of neurons goes along the lines of functional units. In the fly nervous system, neurons and support cells that form a sensory sensillum derive from a common sublineage (Modolell, 1997). But again, cells that form specific types of sensory sensilla in C. elegans (neuron, sheath, socket) rarely have a common lineage history (Sulston, 1983). Synaptically wired neurons also show no special lineage relationship. Due to extensive cell migrations in the developing embryo, neurons in direct proximity to one another are also not necessarily lineally related. 
Another potential classification scheme of neurons is that of a neuron's intrinsic molecular profile. Here again, complex relationships with neuron lineage are evident. Hundreds of reporter gene-based gene expression profiles have been accumulated with single neuron resolution ever since reporter gene technology was established in $C$. elegans (Chalfie et al., 1994). These reporters have generated an enormously useful panel of "molecular descriptors" of individual, terminally differentiated, postmitotic neuron types and are archived in WormBase (see for example, the molecular profile of the AIYL interneuron). The common theme of these expression profiles is all too obvious: rather than being defined by a panel of single neuron-specific genes, neurons are generally defined by the combinatorial co-expression of a set of terminal differentiation genes that individually are expressed in more neuron types (Figure 1C) (Hobert et al., 2010). Intriguingly, most published neuronal gene expression patterns again do not correlate well with lineage history; that is, gene expression profiles do not obviously cluster within groups of lineally related neurons. Figure 1C shows an example of a few genes expressed in AIY and other neuron types; most of the other neuron types show no obvious lineage relation to AIY.

One is therefore left with classifying neurons by specific anatomical features. Based on their electron microscopy work, White et al. (1986) defined 118 neuron classes, with members of individual neuron classes mostly distinguished by their position and common axodendritic projection and connection patterns (see WormAtlas). Neurons classified together by morphology again often do not share common lineage histories; e.g., left/right symmetric neurons that define individual neuron classes (e.g., the left and right AWB neurons that define the "AWB" neuron class) often do not share a common lineage history (see inset in Figure 2). The same applies for individual members of specific motor neuron classes (e.g., the seven DB motor neurons). The often limited relation of similar neurons with lineage essentially means that virtually all neurons are born through asymmetric cell divisions. In other words, only a few pairs of sister cells in the nervous system are similar to one another (e.g., see Figure 5 showing the AIY interneuron and its very distinct sister, the SMDD motor neuron).

Even though similar neuron types can be generated by distinct lineage patterns, some similar neuron types are generated by very similar lineage patterns. This is evidenced by so-called "repeated sublineages", i.e. patterns of cell division that are found at several points in the lineage and that give rise to the same array of neuron types, most often ventral cord motor neurons (Figure 2) (Sulston, 1983; Sulston et al., 1980; Sulston and Horvitz, 1977; Sulston et al., 1983). Repeated sublineages originate from blast cells that may be diverse in their lineage history, but then, through the sublineage pattern, execute a common developmental program. Therefore, similar lineage patterns can, but do not necessarily, produce similar neuron types.

In light of these complexities, how do genetic specification programs in the nervous system work? What is the genetic basis of the impact that lineage does or does not have on neuron specification? Since the introduction of $C$. elegans as a model system by Sydney Brenner in the 1970s, these questions have been addressed using one of the key advantages of the worm model system-forward genetic analysis (Brenner, 1974; Horvitz et al., 1983; Jorgensen and Mango, 2002). The beauty of this approach lies in its largely unbiased nature. One simply isolates mutants in which aspects of nervous system morphology and function (screenable by a variety of means) are disrupted (Horvitz et al., 1983). These genetic studies, as well as a number of reverse genetic studies, have provided key insights into how the nervous system develops (Table 1 provides an overview of neuronal development mutants). Below, I highlight a selected few of these mutants, grouping them by the types of defects observed. Other reviews have ventured more into the details of the development of specific nervous system components, such as the male nervous system, sensory, or motor systems (see Male development; Lanjuin and Sengupta, 2004; Von Stetina et al., 2006). Glial cells are an important component of the C. elegans nervous system (Shaham, 2006), yet an understanding of their development is limited as of now (Yoshimura et al., 2008), and therefore they are not discussed here.

\section{Genes controlling lineage decisions}

\subsection{Neuronal vs. non-neuronal lineage transformations}

Two classic examples of neuronal lineage transformation mutants, lin-32 and lin-22, reveal the existence of defined neuronal vs. non-neuronal "choice points". In animals lacking the atonal-like bHLH transcription factors lin-32, or the achaete-scute-like bHLH gene hlh-14, various lineages that normally produce neurons fail to generate neurons and instead display a fate transformation to skin cells ("hypodermal cells") (Baumeister et al., 1996; Frank et al., 2003; Zhao and Emmons, 1995) (see one lineage example in Figure 3A). Interestingly, the opposite is observed in lin-22 mutants that lack a hairy-type bHLH transcription factor (Figure 3A): lineages normally fated to become skin cells will convert into neurons (Wrischnik and Kenyon, 1997). Epistasis analysis shows that this 
conversion depends on the proneural function of lin-32 (Figure 3A) (Wrischnik and Kenyon, 1997), indicating that some cells have an intrinsic, proneural gene-dependent ability to make neurons, but are actively inhibited by "anti-neural" factors.

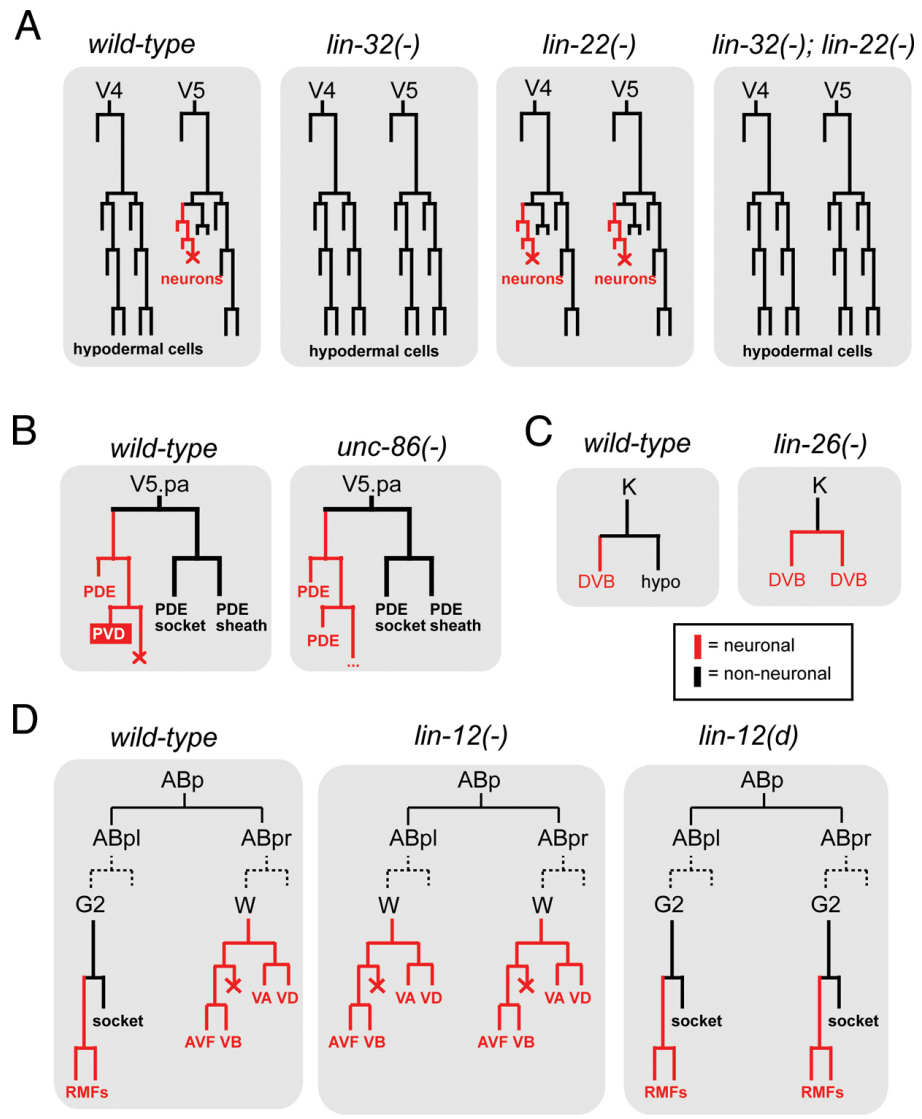

Figure 3. Lineage transformations in specific mutant backgrounds.

(A) Hypodermal cells derived from the postembryonic $\mathrm{V}$ ectoblasts transform into neuronal fates in lin-22 mutants or lose their neuronal fate in lin-32 mutants (Horvitz et al., 1983; Wrischnik and Kenyon, 1997; Zhao and Emmons, 1995).

(B) The V5.pa lineage branch exclusively produces parts of a sensory sensillum (PDE neurons, sheath and socket cells) in the absence of unc-86. unc-86 gene activity determines that the functionally unrelated PVD sensory neuron is generated (Chalfie et al., 1981; Horvitz et al., 1983). Other lineages show similar re-iteration patterns in unc-86 mutants.

(C) A hypodermal cell transforms into a motorneuron (DVB) in lin-26 mutants; many other similar transformations can also be observed in other lineage branches (Horvitz et al., 1983; Labouesse et al., 1994).

(D) One example of the lineage transforming ability of the Notch-like gene lin-12. Notch signaling is thought to occur between the G2 and W cell (Greenwald et al., 1983). Dashed lines indicate that both cells have the same lineage history tracing back to ABpl and ABpr.

Conversions from non-neuronal to neuronal cells are also observed in animals lacking the $\mathrm{Zn}$ finger transcription factor lin-26 (Figure 3C) (Labouesse et al., 1994). Together with the lin-22 phenotype, this is reminiscent of the concept of a "neuronal ground state" in vertebrate neuronal development (Hemmati-Brivanlou and Melton, 1997). In vertebrates, the removal of specific signaling molecules reveals a neuronal ground state that apparently exists in many, if not all, cells but is actively prevented from being executed by inhibitory mechanisms. Consistent with this concept also applying in C. elegans is the depletion of the transcriptional co-activator p300/cbp-1, which results in a derepression of neuronal fate in many C. elegans cell types (Shi and Mello, 1998). Moreover, an embryonic induction mediated by the Notch gene $g l p-1$ can be considered a diversification from a neuronal ground state: in the absence of this induction both bilaterally homologous ABara and ABala lineages produce only neurons, while in the presence of $g l p-1$ the ABara lineage produces neuronal and non-neuronal cells (Hutter and Schnabel, 1994). Taken together, in analogy to the vertebrate system, neuronal fate may be the "default" specification program in many lineages that is modified through the action of specific gene products. 


\subsection{Neuron lineage alterations and losses}

Transcription factors that act downstream of lin-32 or hlh-14 confer specific identities to individual lineages. Genetic determinants of neuronal lineage identity were again first uncovered through genetic screens for mutants in which nervous system function is disrupted. The most prominent example is the Brn3-like unc-86 POU homeobox gene (Chalfie et al., 1981; Finney and Ruvkun, 1990; Finney et al., 1988). Its loss results in a specific set of neuronal lineage transformations (Figure 3B). One very intriguing aspect of these transformations is that they reveal an underlying "stem cell-like" division pattern, in which, in the absence of unc-86, a mother cell continues dividing to re-generate itself and to produce a neuron that terminally differentiates (Chalfie et al., 1981). Therefore, unc-86 is a lineage-modifier that imposes an activity on a perhaps more ancient and simpler lineage pattern to generate novel neuronal identities.

HOX cluster genes also determine specific neuronal lineage patterns. One example is the AbdB-like HOX cluster gene egl-5. Six ray lineages in the male tail produce a stereotyped set of sensory neurons (and support cells), each with a specific identity scorable by neurotransmitter/peptide-expression profiles (Lints et al., 2004). In egl-5 mutants, several of the ray lineages convert to one specific ray identity (Lints et al., 2004). HOX cluster genes also pattern anterior/posterior identities of ectodermal blast cells that generate repeated patterns of motor neuron types (Salser and Kenyon, 1994). In analogy to HOX cluster genes in other organisms, HOX genes are expressed in consecutive anterior/posterior domains along the body axis. Intriguingly though, the regional specificity of their gene expression is not controlled by regional cues, but is strictly determined by a lineal mechanism (Cowing and Kenyon, 1996; Wittmann et al., 1997).

The loss of a transcription factor that controls the identity of individual neuron lineages does not, however, necessarily result in the transformation of the neuroblast to another identity. One example is the tailless-like orphan nuclear hormone receptor $n h r-67$, which is required to specify the identity of several different neuroblasts, each producing a subset of distinct neurons (Sarin et al., 2009). Loss of $n h r-67$ does not appear to result in the execution of an alternative lineage program, but may result in the simple failure of all neurons in this lineage to adopt any specific subtype identity (they will still form neurons, however)(Sarin et al., 2009). Similarly, loss of the NeuroD-type bHLH gene cnd-1, which like unc-86 and $n h r-67$ is expressed in many unrelated lineages, results in broad lineage proliferation and specification defects, but not in obvious lineage transformations (Hallam et al., 2000). Whether loss of a lineage identity determinant results in a loss or in a transformation of the lineage identity must obviously depend on the absence or presence of factors regulating alternative programs that would drive lineages towards an alternative fate. The theme of failure to differentiate vs. switching to alternative fate will be reiterated below when I discuss factors that act in postmitotic neurons to control their terminal fate.

Neuron lineage transformations are not only observed upon removal of transcription factors. Several neuronal lineage transformations occur upon altering the activity of the lin-12/Notch signaling system (Greenwald, 1989; Horvitz et al., 1983). For example, lin-12 signaling between a pair of bilaterally symmetric cells, an ectoblast (G2) and a neuroblast (W), distinguishes these two lineages: removal of lin-12 results in a G2 to W transformation, while constitutively active lin-12 results in a W to G2 transformation (Figure 3D). Both G2 and W are therefore equipotent cells and select their fate through a classic "lateral inhibition" process (Greenwald, 1998).

Genes that control neuroblast identity often also have later roles in terminal neuron differentiation. This is again exemplified by two of the genes mentioned above, unc-86/POU and $n h r-67 /$ Tailless. unc-86 affects the lineage that generates the touch sensory neurons, but also acts in the mature touch neurons to directly regulate the expression of terminal differentiation features (Chalfie and Sulston, 1981; Duggan et al., 1998). nhr-67 is required for the identity of a neuroblast that generates several sensory and interneurons, but continues to be expressed in one lineage subbranch to control a small and restricted subset of terminal identity features of a postmitotic sensory neuron in this lineage (Sarin et al., 2009).

\section{Genes controlling neuron class specification}

Many genes that control neuronal specification have traditionally been identified through forward genetic screens for mutants in which individual neuron classes with easily scorable functions or morphologies (for example motorneurons or sensory neurons) either do not differentiate or function appropriately, resulting in characteristic behavioral defects (such as sensory defects or locomotory defects) (Brenner, 1974; Dusenbery et al., 1975; Hedgecock and Russell, 1975; Horvitz et al., 1983). Searching for viable behavioral mutants may have introduced a bias to the types of genes identified. Rather than identifying genes that control early patterning in the nervous system (whose loss would be expected to cause pleiotropic effects), these screens largely identified gene regulatory factors 
that act at late stages of neuronal development, most often during terminal differentiation of a select number of postmitotic neurons (Table 1).

\subsection{Terminal selectors control terminal neuron identity}

Several genes identified in screens for behavioral mutants uncovered transcription factors with remarkably similar effects on the differentiation of individual neuron types. Four particularly well characterized examples are mec-3 mutants, isolated for defects in mechanosensory behavior (Way and Chalfie, 1988); ttx-3 mutants, isolated for defects in thermotaxis behavior (Hedgecock and Russell, 1975; Hobert et al., 1997); unc-30 mutants, isolated for defects in locomotory behavior (Jin et al., 1994); and che-1 mutants, isolated for defects in chemotaxis behavior (Chang et al., 2003; Dusenbery et al., 1975; Uchida et al., 2003). In each respective mutant a set of neurons required for the execution of the individual behavior completely fails to differentiate. In mec-3 mutants mechanosensory neurons fail to differentiate, in $t t x-3$ mutants an interneuron class (AIY) required for processing thermosensory information shows differentiation defects, in che-1 mutants a key gustatory neuron class (ASE) fails to differentiate, and in unc-30 mutants GABAergic motor neurons in the ventral nerve cord do not differentiate appropriately. Molecular markers that are normally expressed in these types of neurons have drawn a very similar picture about what kind of differentiation defect is observed in these mutants: the combinatorial gene expression profile that defines the terminal identity of each individual neuron ("terminal gene battery") is essentially completely wiped out (Altun-Gultekin et al., 2001; Cinar et al., 2005; Duggan et al., 1998; Eastman et al., 1999; Etchberger et al., 2007; Uchida et al., 2003; Wenick and Hobert, 2004; Zhang et al., 2002). As an example, Figure 1C shows AIY identity determinants, which all fail to be expressed in $t t x-3$ mutants. Yet in all the mutant animals, the respective neuron is still present and even still appears to express pan-neuronal features. Obvious transformations to other cell identities are in some cases observed (e.g., the ALM neuron converts to its BDU sister if the mec-3 terminal selector is mutated (Kim and Li, 2004; Way and Chalfie, 1988)) but in other cases are not apparent (e.g., ttx-3 or che-1), suggesting that in the respective mutants the neurons may reside in some undifferentiated "default" or "ground state".

The analysis of the cis-regulatory architecture of terminal differentiation gene batteries that define the neurons mentioned above reveals another striking common theme. These terminal differentiation batteries appear to be co-regulated by a common cis-regulatory motif (Cinar et al., 2005; Duggan et al., 1998; Eastman et al., 1999; Etchberger et al., 2007; Flames and Hobert, 2009; Wenick and Hobert, 2004; Zhang et al., 2002). For example, the genes shown in Figure 1C all contain a so-called "AIY motif", a motif that is required and sufficient to drive expression in the AIY interneuron class (Wenick and Hobert, 2004). Similar shared motifs can be found in mechanosensory neurons, dopaminergic neurons, gustatory neurons and GABAergic D-type ventral cord neurons. The genes described above, which control the fate of the respective neuron classes, all code for postmitotically expressed transcription factors that directly bind those cis-regulatory motifs (Figure 4). These "master regulatory" transcription factors-mec-3, unc-30, che-1, ttx-3-have been termed "terminal selectors" (Hobert, 2008).

Terminal selectors are required to initiate terminal differentiation programs after the terminal division of a neuron, and their continuous activity throughout the life of a neuron is required to maintain the identity of a neuron (Hobert, 2008). Terminal selectors are critical nodes in a regulatory hierarchy, integrating various upstream lineage inputs (Bertrand and Hobert, 2010) (see below). But terminal selectors are not regulatory end points in defining neuronal identities. Even though they control many terminal differentiation features directly, they also induce the expression of other regulatory factors. Those downstream factors regulate restricted aspects of the identity of a specific neuron type. For example, in the AIY interneuron the ceh-23 homeobox gene, a target of the ttx-3 terminal selector, serves to specifically regulate expression of a G-protein coupled receptor sra-11 (Altun-Gultekin et al., 2001), a behavioral plasticity gene (Remy and Hobert, 2005) (Figure 4). Similarly, the che-1 terminal selector, which directly induces the expression of many terminal differentiation genes in the ASE gustatory neurons, also controls the expression of various regulatory factors that diversify the two ASE sensory neurons (Etchberger et al., 2009; Etchberger et al., 2007; Hobert, 2006) (see further below). 

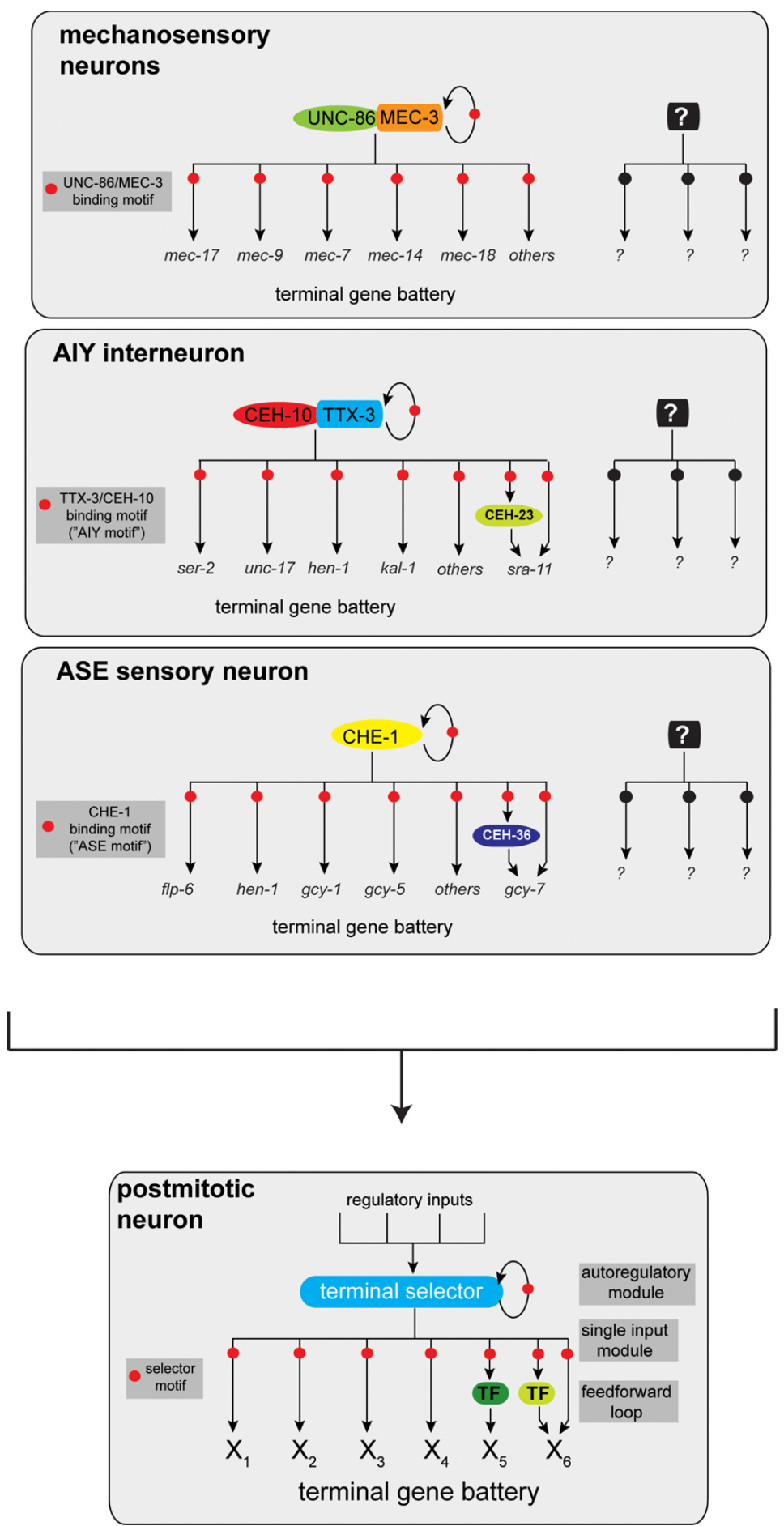

Figure 4. Terminal selectors define neuronal identity. Three examples of terminal selector transcription factors that co-regulate batteries of genes that define the identity of an individual neuron type (Hobert, 2008). Terminal selectors autoregulate their expression, thereby ensuring the maintained expression of their targets throughout the life of a neuron. Terminal selectors may also regulate transcription factors that regulate specific subaspects of a neuron's identity. Other well-studied terminal selectors are the Pitx2-type homeobox gene unc-30, which controls GABAergic neuron identity and the ETS factor ast-1, which controls dopaminergic neuron identity. As both factors are expressed in more neuron types, they likely pair up with as yet unidentified co-factors. The same principle applies to the AIY terminal selectors $t t x-3$ and ceh-10: both factors are expressed in more cells than AIY but uniquely overlap in AIY (see Figure 1C). Note that other regulatory routines act in parallel to terminal selector genes. For example, terminal selectors tend not to affect the expression of pan-neuronal genes; those may be co-regulated by other factors (Ruvinsky et al., 2007). Also note that one central feature of the terminal selector concept is its "hourglass"-shaped regulatory topology, as indicated in the panel on the bottom: multiple regulatory inputs funnel into the establishment of terminal selector gene expression, a regulatory bottleneck. Once established, downstream regulatory events then again fan out. Table 1 lists additional candidate terminal selector genes. 
Terminal selectors control neuronal identity on a very broad level. Their targets include scores of "nuts-and-bolts" differentiation determinants, including one central, core identity feature of a neuron, its neurotransmitter identity. Neurotransmitter identity is usually defined by a battery of genes that code for proteins that synthesize, package and re-uptake neurotransmitter. Investigations into the regulatory logic of the neurotransmitter identity of each gene have shown that such batteries are indeed co-regulated by common cis-regulatory motifs that are activated by similar trans-acting factors. Those trans-acting factors are terminal selectors. The homeobox terminal selector unc-30 is the first example of such co-regulatory logic. Two key enzymes for GABA synthesis and transport are directly co-regulated by unc-30 in ventral cord motor neurons (Eastman et al., 1999). Subsequently, it was found that unc-30 does not just determine GABA neurotransmitter identity, but also other identity features of ventral cord motor neurons (Cinar et al., 2005). The same principle applies to dopaminergic neurons: the gene battery controlling dopaminergic neuron identity is co-regulated by a common cis-regulatory motif and trans-acting factor, the ETS domain factor ast-1 (Flames and Hobert, 2009). ast-1 also regulates other terminal features of dopaminergic neurons and therefore constitutes a terminal selector. At least some cholinergic neurons may be regulated by a similar principle as well.

Neurons that share a common neurotransmitter identity can be very diverse otherwise: e.g., acetylcholine is utilized by vastly distinct sets of neuron types. Within these distinct neuron types, neurotransmitter identity is under co-regulatory control by neuron-type specific terminal selectors. For example, the $t t x-3$ terminal selector determines the cholinergic phenotype of the AIY interneuron class (Altun-Gultekin et al., 2001), while cholinergic ventral cord neurons appear to be under control of the putative terminal selector unc-3 (Von Stetina et al., 2006). From the perspective of the neurotransmitter gene battery, this means that genes that define neurotransmitter identity (e.g., the vesicular AcCh transporter unc-17) contain in their cis-regulatory control region a modular array of binding sites for distinct terminal selector genes. The results of the mutational dissection of the cis-regulatory control regions of genes such as unc-17 are consistent with such logic (Wenick and Hobert, 2004).

With only a few examples at hand, it is not clear whether the terminal selector concept applies to all neurons in the nervous system. Future work will address this issue. At this point there are plenty of candidate terminal selectors (Table 1). A closer inspection of cell fate markers in the respective mutants is required to assess whether these candidates are indeed terminal selectors. The principle of co-regulation of terminal gene batteries also requires further, comprehensive validation through mutational dissection of cis-regulatory elements in the context of reporter genes, as exemplified in previous studies (Duggan et al., 1998; Eastman et al., 1999; Etchberger et al., 2007; Flames and Hobert, 2009; Wenick and Hobert, 2004).

\subsection{Combinatorial regulatory codes}

CHE-1, a Zn finger transcription factor, is a terminal selector for the ASE gustatory neuron class, activating scores of target genes via a small cis-regulatory motif, the ASE motif. CHE-1 is exclusively expressed in the ASE neuron class (Sarin et al., 2009) and is therefore an exception, as virtually no other known terminal selector is exclusively expressed in only one neuron class (one possible exception being the ODR-7 orphan nuclear receptor, a candidate terminal selector for AWA (Sengupta et al., 1994)). For example, $t t x$-3, a LIM homeobox terminal selector for the AIY interneuron, is expressed in at least three other neuron classes (Altun-Gultekin et al., 2001). In those other neuron classes it does not appear to act as a terminal selector. The solution to this apparent conundrum is the use of combinatorial regulatory codes. $t t x-3$ does not act alone as a terminal selector, but acts together with ceh-10, another terminal selector for AIY (Figure 4). Both proteins together form a heterodimer exclusively in AIY (the only cell where the expression of the two transcription factors overlaps) to bind to their cognate DNA binding site, the AIY motif, in a cooperative manner (Wenick and Hobert, 2004). The classic example of a terminal selector, unc-86 and mec-3, works by the same principle: unc-86 is expressed in many neurons but heterodimerizes exclusively in touch sensory neurons with mec-3, where it induces terminal differentiation genes of touch neurons by binding to a motif present in genes encoding the mechanosensory apparatus of those neurons as well as many other terminal differentiation genes (Duggan et al., 1998; Xue et al., 1992; Xue et al., 1993; Zhang et al., 2002). unc-86 may act as a terminal selector in other neuron types, where it may cooperate with other transcription factors to induce a distinct set of downstream target genes.

Consistent with the combinatorial regulatory logic, the coupling of gene regulatory factors to specific effector outputs is not conserved in individual cell types. For example, the lim-6 LIM homeobox gene regulates the expression of the GABA synthesizing enzyme unc-25 and the glutamate receptor $g l r-1$ in the RIS interneuron but, although all three genes are co-expressed in the RME motorneurons, lim- 6 does not regulate the expression of either gene in this cell type (Tsalik et al., 2003). Other examples are the ttx-3 and ceh-23 homeobox genes whose 
expression overlaps in both AIY and ADL: ttx-3 regulates ceh-23 in AIY but not in ADL where, in contrast to AIY, ttx-3 does not act as a terminal selector gene (Altun-Gultekin et al., 2001). "Once a terminal selector" therefore does not mean "always a terminal selector", another illustration of context dependency of transcription factor action. Combinatorial regulatory codes also provide a simple explanation for why many transcription factors that have central roles in neuronal specification are also expressed in non-neuronal cells where they apparently collaborate with distinct sets of transcription factors. They also explain how factors such as $u n c-86$ or $n h r-67$ can have distinct roles early and late in the development of a neuronal lineage.

\subsection{Other regulatory routines in terminally differentiated neurons}

Several separable regulatory programs seem to operate in parallel in a terminally differentiated neuron (Figure 4). First, there are a neuron's individual identity features, which may be controlled broadly by terminal selectors. Yet, some aspects of terminal neuron identity appear unaffected by terminal selectors and therefore constitute separate regulatory routines. All sensory neurons, as diverse as they may be in terms of lineage and morphology, appear to contain shared regulatory programs to control core features of dendritic cilia. This regulatory program depends on a co-regulatory logic, as evidenced by a shared cis-regulatory motif ("X box") present in scores of genes whose products build core features of sensory cilia. This motif is bound and mediates activation by the RFX-type factor DAF-19 (Efimenko et al., 2005; Swoboda et al., 2000). As DAF-19 directly controls co-regulated terminal identity features that generate a defined feature of the neuron, it can also be considered a terminal selector (of ciliogenesis). Pan-neuronal features shared by all neurons also appear to be controlled by a separable regulatory routine since, with a few notable exceptions, pan-neuronal fate is often not affected by terminal selectors. Moreover, the identification of a cis-regulatory motif in many (but not all) pan-neuronally expressed genes suggests the existence of co-regulatory mechanism for pan-neuronal fate (Ruvinsky et al., 2007). Trans-acting factor(s) that work through the shared cis-regulatory motif are not yet known.

Genetic screens have also revealed a number of transcription factor mutants in which neuronal identity is apparently unaffected, but in which axon pathfinding defects (e.g., ast-1, zag-1, ceh-17, lin-11 mutants (Hobert et al., 1998; Pujol et al., 2000; Schmid et al., 2006; Wacker et al., 2003)) or neuronal migration defects are observed (e.g., mab-5, ham-2 mutants (Baum et al., 1999; Salser and Kenyon, 1992)). Usually these defects are not reflective of a switch in the identity of a neuron to that of another neuron with a distinct morphology. How regulatory routines that affect neuronal migration and morphology are connected to terminal selectors is not yet known; they may act downstream of terminal selectors or in parallel.

\section{Genes controlling neuron subclass specification}

\subsection{Diversifying motor neuron classes}

Based on their anatomical features, ventral cord motor neurons can be divided into specific classes, including the A, B, C and D-type motor neurons. All these neurons require, at least in part, the pro-neural NeuroD-like bHLH gene cnd-1 for their generation (Hallam et al., 2000). How do different types of motor neurons then become specified? A- and B-type motor neurons are cholinergic, share morphological similarities and co-express a number of genes, yet are distinct based on sub-batteries of A- and B-type specific genes and synaptic connectivity (Fox et al., 2005; Von Stetina et al., 2006). Whether both A- and B-type motor neurons are specified by a common terminal selector gene is presently unknown; the O/E-type transcription factor unc-3 is a candidate for such a factor (Prasad et al., 1998; Von Stetina et al., 2006). A series of negative regulatory interactions act to diversify A- and B-type motor neurons. A key player in this process is the unc-4 Prd-type homeobox gene and its Groucho-like co-factors unc-37 and lsy-22 (Flowers et al., 2010; Miller et al., 1992; Winnier et al., 1999). In animals lacking the unc-4 homeobox gene, the postembryonically born A-type motor neurons (VA subclass) adopt the fate of the B-type neurons (VB subclass) (Miller and Niemeyer, 1995; Winnier et al., 1999). unc-4 acts via a downstream homeobox gene, the HB9-like ceh-12 gene (Von Stetina et al., 2007).

Such an "alternative fate switch" theme is also apparent in another major class of ventral cord motor neurons, the GABAergic D-type motorneurons. D-type motor neurons can be subdivided into embryonically (DD) and post-embryonically (VD)-born D-type motor neurons, with distinct muscle innervation properties. Both types require the unc-30 terminal selector, a Pitx-type homeobox gene, as described above. The unc-55 orphan nuclear receptor is then required to distinguish these two distinct subclasses. In the absence of unc-55 the VD-subclass adopts the fate of the DD-subclass (Zhou and Walthall, 1998). 
Ventral cord motorneurons are not the only type of motor neurons that require functional diversification. $C$. elegans contains more than 30 head motor neurons that can be classified into several types, with each type being again classified into subclasses. The RME motorneuron class, composed of four radially symmetric cells, RME left, RME right, RME dorsal and RME ventral, is one example. The $a h r-1 \mathrm{Zn}$ finger transcription factor imposes a RMEL/R "fate" onto on apparent "RMED/V" ground state that is executed by all four neurons (Huang et al., 2004). That is, loss of $a h r-1$ causes all four RME neurons to express RMED/V markers, while ectopic expression of ahr-l in all four RME neurons induced the RMEL/R fate. This demonstrates that, at least in some cases, neuron subclasses are diversified from a "neuron class ground state" common to all class members, with the diversification being brought about by the superimposition of a regulatory routine onto a subset of the class members.

\subsection{Diversification across the left/right axis}

Neural fate diversification can also be observed across the left/right axis. Most neuron classes in the nervous system are composed of a pair of two bilaterally symmetric neurons (Hobert et al., 2002; Sulston, 1983). While most known left/right bilateral analogs are indistinguishable from one another based on anatomic, functional and gene expression criteria, the bilaterally symmetric AWC olfactory and ASE gustatory neurons express different sets of putative chemoreceptors in the left vs. right neuron and, therefore, have diverged their chemosensory capacities (Pierce-Shimomura et al., 2001; Troemel et al., 1999; Wes and Bargmann, 2001; Yu et al., 1997). In the case of ASE, this appears to be programmed in an invariant manner into the ASEL and ASER lineages (Poole and Hobert, 2006). Diversifying from a "bilaterally symmetric ground state", induced by the che-1 $\mathrm{Zn}$ finger terminal selector, a regulatory network of several homeobox genes and microRNAs is required to make ASEL and ASER different from each other (Hobert, 2006; Johnston et al., 2005). These factors do not act linearly, but constitute a "bistable feedback loop". The negative regulatory interaction between individual regulatory factors in this loop ensures that the loop can exist in two states (hence "bistable"). In the ASEL cell the output of the loop is the induction of a very specific subset of ASEL fate markers, while in the ASER cell the loop operates with the "opposite" sign, thus causing the induction of the ASER fate. The theme observed here is similar to that of motor neuron class specification. A common ground state (che-l-induced bilateral ASE fate) is modified through superimposed regulatory interactions. The novel feature of the ASE example is that it relies on at least one miRNA (Johnston and Hobert, 2003).

In contrast to the stereotyped ("directional" (Palmer, 1996)) asymmetry of the ASE neurons, AWC asymmetry is stochastic ("antisymmetry" (Palmer, 1996)) and controlled by a distinct, non-lineage-dependent mechanism that relies on direct contact between the two neurons and a calcium-triggered signaling cascade (Lesch et al., 2009; Sagasti et al., 2001; Troemel et al., 1999). As in the ASE case, this regulatory pathway diversifies a ground state induced by what is a likely terminal selector, the ceh-36 Otx-type homeobox gene (Lanjuin et al., 2003; Lesch et al., 2009). The stochastic nature of AWCL vs. AWCR fate choice is an intriguing indication of not all terminal fate choices being entirely lineage programmed.

Left/right asymmetric gene expression is also observed in the RIFL/R neuron pair (Wadsworth et al., 1996) and the AIYL/R neuron pair (Vincent Bertrand and Oliver Hobert, unpublished data). Careful examination of reporter gene expression profiles are expected to reveal more lateralities; i.e. fate diversifications across the left/right axis, an elegant strategy to make the best use of the limited neuron number C. elegans has at its disposal.

\section{Linking neuronal class specification to lineage}

Hierarchical layers of transcription factor codes are a relatively straightforward way to envision how cell lineage and history are coupled to terminal neuronal fates. At each developmental stage, an individual neuroblast may contain a specific and unique combination of transcription factors which are required to select the next level of transcription factor combinations. Work over the past few years has shown that lineage-specific transcription factor codes may be brought about by a lineage-intrinsic coordinate system (Kaletta et al., 1997; Lin et al., 1998). Lin et al. (1998) observed that the TCF/LEF1-like transcription factor pop-1, an output regulator of Wnt signaling, is asymmetrically distributed in the anterior (high levels in nucleus) and posterior (low levels in nucleus) daughter of virtually every cell division in the early embryo. Work over the past few years has extended this observation to many more cell divisions during later stages of embryonic and postembryonic development within and outside the nervous system (reviewed in Mizumoto and Sawa (2007) and Phillips and Kimble (2009)). Moreover, a mirror image asymmetric distribution of the POP-1 transcriptional co-factor $\beta$-catenin/SYS-1 has been discovered (Phillips et al., 2007). This provides a clear molecular correlate to the "binary lineage descriptor" of every cell in the worm; e.g., ABplpapaaap is AIYL, with "AB" indicating the name of a blastomere at the two cell stage that generates the vast majority of the nervous system, "l" indicating divisions across the left/right axis and "a"/"p" indicating 
divisions with an anterior/posterior cleavage plane (Figure 5). In other words, the POP-1/SYS-1 asymmetric distribution observed upon every single cell division translates a sequence of $\mathrm{a} / \mathrm{p}$ cell cleavages in a defined transcription factor history in which every single cell in the animal has experienced a specific sequence of POP-1/SYS-1 regulatory states (high or low) (Figure 5).

Far from being a mere correlate, the POP-1/SYS-1 code is indeed instructive and predictive, as has been shown at various stages of development through the manipulation of the Wnt signaling system that alters POP-1/SYS-1 levels (Kaletta et al., 1997). For example, within the nervous system one of these experimental manipulations raises the levels of POP-1 in the posterior cell of the terminal, asymmetric cell division that generates the two neurons SMDD (anterior) and AIY (posterior) and results in a transformation of AIY to SMDD (Bertrand and Hobert, 2009). How neuronal identity determinants, i.e. neuronal terminal selectors, intersect with the POP-1/SYS-1 system has recently been elucidated in the context of the AIY/SMDD asymmetric cell division and is shown in Figure 5. The transiently expressed Zic-like ref-2 Zn finger transcription factor cooperates with a combination of at least two transiently expressed bHLH genes to directly activate expression of the $t t x-3$ terminal selector in the mother of AIY (Bertrand and Hobert, 2009). TTX-3 protein is then symmetrically segregated to the daughters of this cell, AIY and its sister neuron SMDD, yet TTX-3 is only maintained in AIY. This is because TTX-3 acts in conjunction with POP-1/SYS-1, which is only active in AIY and not in SMDD, to activate its partner protein CEH-10. TTX-3 and CEH-10 then automaintain their expression and induce the terminal AIY gene battery (Figure 5). Manipulations that alter activity of the POP-1 system have been undertaken in different lineages and at different stages of embryonic neuronal development, revealing the ubiquitous employment of the system (Bertrand and Hobert, 2009).

There are a number of genes that act in neuroblasts to determine their identity and they may act in analogy to the coupling of the neuroblast identity determinant $r e f-2$ to a terminal selector. For example, the nhr-67 orphan nuclear receptor is expressed transiently in multiple neuroblasts to determine their identity and activates two terminal selector genes in two different types of neuroblasts, che-1 and lim-4 (Sarin et al., 2009). Similarly, the unc-130 Forkhead transcription factor acts together with the aristaless-like gene alr- 1 in a neuroblast that generates two distinct chemosensory neurons, AWA and ASG, and again both genes may activate, directly or indirectly, candidate terminal selector genes for each sensory neuron (odr-7 for AWA and lin-11 for ASG) (Melkman and Sengupta, 2005; Sarafi-Reinach et al., 2001; Sarafi-Reinach and Sengupta, 2000). How the POP-1/SYS-1 system intersects with these factors is not yet known.

Transcription factors that initiate and maintain the identity of a neuron (i.e. terminal selectors) are not necessarily activated in the mother cell, as there are other transiently expressed activators of terminal selector genes that are only expressed in a short time window after the neuron is born. One example is the HMX-type homeobox gene $m l s-2$, which is transiently expressed in the AWC neuron shortly after its birth to then activate the likely terminal selector of AWC fate ceh-36, an Otx-type homeobox gene (Kim et al., 2010). Again, it is not clear yet how the POP-1/SYS-1 system interacts with those factors, but the emerging overall logic is that progressive "waves" of transcription factor activity are combined with asymmetric POP-1 cues to provide unique identities to individual neuroblasts and terminally differentiating neurons.

Specifying neuronal identities by a series of binary codes may provide the key to resolve the complex relationships between lineage and fate, discussed at the beginning of this review. Much like the classic genetic code, the binary lineage code may be degenerate in the sense that two different sets of codes (i.e. two different sets of transcription factor histories) may specify the same terminal fate (applicable for example, to the AWBL and AWBR neurons, two morphologically, molecularly and functionally indistinguishable neurons with distinct lineage histories as shown in the inset to Figure 2). 


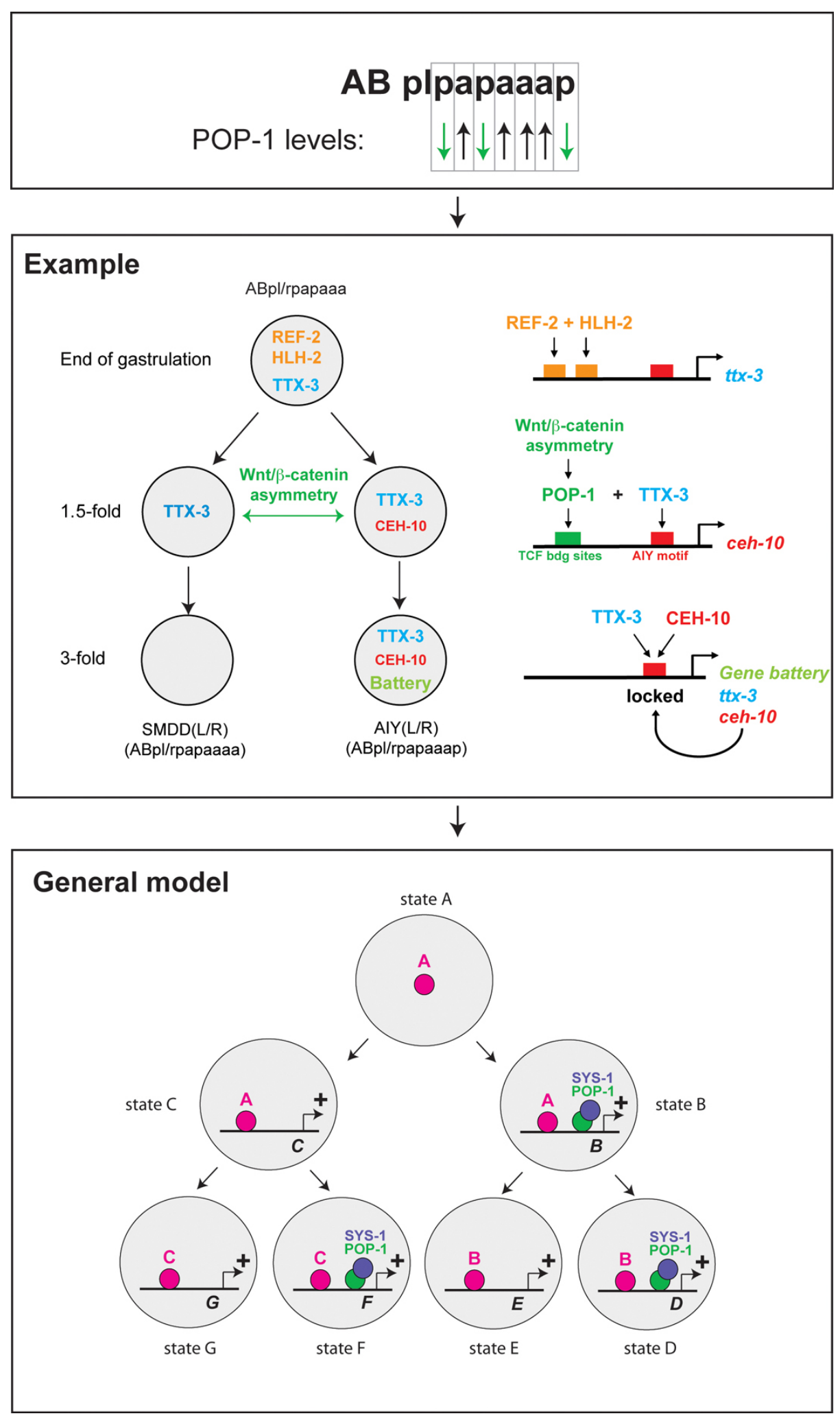

Figure 5. A Wnt signaling system contributes a lineage specific transcription factor code acting throughout the nervous system. Cleavage patterns of individual cells can be translated into high/low levels of POP-1 (and reciprocal SYS-1 levels). Together with successively activated transcription factors, POP-1/SYS-1 may act to establish cell-specific transcription factor codes. The Wnt/ $\beta$-catenin asymmetry pathway acts broadly throughout the nervous system (Bertrand and Hobert, 2009; Mizumoto and Sawa, 2007). The model in the lower panel is an updated version of the concept initially proposed by Lin et al. (1998) and was adapted from Bertrand and Hobert (2010). The middle panel is adapted from Bertrand and Hobert (2009). For a more in-depth discussion of the Wnt/ $\beta$-catenin asymmetry pathway, see Mizumoto and Sawa (2007) and Phillips and Kimble (2009). 
Even though the POP-1/SYS-1 system seems to be very broadly acting, another system, mediated by the novel, cortically-localized non-conserved HAM-1 protein and the PIG-1 protein kinase, serves to asymmetrically segregate lineage determinants in a restricted number of neuroblasts, (Cordes et al., 2006; Frank et al., 2005; Guenther and Garriga, 1996). Intriguingly, HAM-1 controls only neuroblast divisions that produce apoptotic cells (Frank et al., 2005). If and how HAM-1 interacts with the POP-1/SYS-1 system is not known. It is also not known how a Wnt-dependent signaling event can operate at every single cell division throughout the developing organism. Even though a Wnt-receptor and downstream signaling components that regulate POP-1 and SYS-1 asymmetry have been identified (Mizumoto and Sawa, 2007; Phillips and Kimble, 2009), the source of the ligand for this global coordinate system in the embryonic nervous system has not yet been reported. A relay mechanism from cell to cell has been proposed, at least for some embryonic divisions (Bischoff and Schnabel, 2006).

The POP-1/SYS-1 system (also termed the Wnt/ $\beta$-catenin asymmetry pathway (Mizumoto and Sawa, 2007)) illustrates the importance of non-autonomous signaling events in neuronal lineage determination, a notion that was initially much underappreciated (Sulston, 1983). Other prominent examples include Notch signaling, which serves to control lineage identity at various stages of neuronal development (as mentioned above), and TGF $\beta$-like signaling, which plays a prominent role in controlling neuroblast and terminal neuronal identities in the male sensory neuron system, discussed in more detail in the chapter Male development.

\section{Conclusions and perspectives}

I have reviewed here some general features of $C$. elegans nervous system development and highlighted some emerging principles. The analysis of many, but not all, genes that act at different stages of neuronal development (neuron vs. non-neuron, lineage specification, terminal neuron differentiation, subtype specification) reveals a common theme observed across the animal kingdom-triggering a specific developmental program may rely as much on positive induction as it does on repressing alternative fates. This has been mentioned for some isolated cases above, but it is worth reiterating to underscore the common thread: in lin-22 mutants neuronal fate will be executed instead of hypodermal fate; in the postdeirid lineage loss of unc-86 results in the loss of the PVD and gain of the PDE neuronal fate; in the terminal selector mutant mec-3 some touch neurons adopt the fate of their sisters; in lim-4 mutants the AWB neuron switches to the AWC neuron; in unc-4 and vab-7 mutants ventral cord motor neuron classes execute alternative fate programs (Von Stetina et al., 2006); in ahr-1 mutants RMEL/R neurons change their identity to RMED/V neurons (Huang et al., 2004); in $\operatorname{cog}-1$ or die-1 mutants two left/right asymmetric neurons switch fate (Hobert, 2006); and etc. Often, but not always, the alternative fate bears no obvious lineage relationship to the original fate. Alternative fate switches essentially mean that a specific regulatory program is induced in multiple cells but repressed in a subset of those. Repression of one fate goes alongside with inducing a novel fate. However, the mechanistic basis for this switch behavior is mostly unclear. For example, does unc-86 act as an activator to induce PVD fate and as a repressor to directly inactivate PDE fate (via repressing the PDE terminal selector ast-1) (Figure 3), or does unc-86 only work as an activator and repress PDE fate by activating a repressor of PDE fate? Notably though, alternative fate switches do not always occur. In spite of extensive analysis with cell fate markers, no alternative fates appear to be executed in the absence of the terminal selector che- 1 in ASE or ttx-3 in AIY (Altun-Gultekin et al., 2001; Uchida et al., 2003). In such cases, the identity of a neuron (e.g., ASE) is not a derivative of a ground fate that has become diversified through superimposition of an additional regulator.

As described above, two additional specific hypotheses have been developed over the past decade and will require systematic testing. The first deals with terminal neuronal differentiation and posits the existence of "master-regulatory" terminal selectors which co-regulate large batteries of identity determinants. How prevalent such logic is, compared to a more haphazard, piece-meal logic, will require a broad systematic analysis of many different neuron classes. The appeal of the simplicity of the terminal selector concept lies, in part, in its similarity to regulatory strategies in much simpler systems such as bacterial regulons (Hobert et al., 2010). The other key concept that requires further development is the Wnt/POP-1 system. Where does the ligand come from? What exactly are all the transcription factors with which the POP-1/SYS-1 transcription factor system interacts? That is, what is the precise nature of the regulatory states in each neuroblast during development? Systematic mapping of transcription factor expression profiles in a comprehensive 4D manner (i.e. mapping in time and space (Murray et al., 2008)) as well as molecular strategies to identify POP-1 target genes will be an important step into this direction. Other than hypothesis testing, forward genetic screening for neuronal development mutants, the classic tool of the C. elegans trade, will surely continue to reveal novel insights into nervous system patterning. Recent technological advances, including the automated sorting for neuronal fate mutants (Doitsidou et al., 2008) or whole genome sequencing for mutant identification (Hobert, 2010) will help in this endeavor. 
Finally, which of the concepts of neuronal differentiation defined in C. elegans also apply to more complex nervous systems? It is apparent that general principles such a pro-neuronal control mechanisms, repression of ground states, combinatorial transcription factor interactions, and co-regulation of terminal differentiation genes appear conserved (Guillemot, 2007; Hobert et al., 2010). Moreover, it is notable that not only do most of the regulatory factors listed in Table 1 have clear vertebrate orthologs (see WormBase), but some transcription factor-neuronal target gene interactions are conserved between C. elegans, Drosophila and vertebrates as well (Flames and Hobert, 2009; Laurencon et al., 2007). Studies in C. elegans will therefore continue to help us understand how nervous systems develop.

\section{Acknowledgements}

Work in my laboratory is funded by the NIH (R01NS039996-05; R01NS050266-03) and the Howard Hughes Medical Institute. I thank members of my laboratory for comments on the manuscript. This chapter is an update of Hobert, O. Specification of the nervous system (August 8, 2005), WormBook, ed. The C. elegans Research Community, WormBook, doi/10.1895/wormbook.1.12.1.

\section{References}

Altun-Gultekin, Z., Andachi, Y., Tsalik, E.L., Pilgrim, D., Kohara, Y. and Hobert, O. (2001). A regulatory cascade of three homeobox genes, ceh-10, ttx-3 and ceh-23, controls cell fate specification of a defined interneuron class in C. elegans. Development 128, 1951-1969. Abstract

Baum, P.D., Guenther, C., Frank, C.A., Pham, B.V. and Garriga, G. (1999). The Caenorhabditis elegans gene ham-2 links Hox patterning to migration of the HSN motor neuron. Genes Dev. 13, 472-483. Abstract

Baumeister, R., Liu, Y. and Ruvkun, G. (1996). Lineage-specific regulators couple cell lineage asymmetry to the transcription of the Caenorhabditis elegans POU gene unc-86 during neurogenesis. Genes Dev. 10, 1395-1410. Abstract

Bertrand, V. and Hobert, O. (2009). Linking asymmetric cell division to the terminal differentiation program of postmitotic neurons in C. elegans. Dev. Cell 16, 563-575. Abstract Article

Bertrand, V. and Hobert, O. (2010). Lineage programming: navigating through transient regulatory states via binary decisions. Curr. Opin. Genet. Dev. 20,362-368. Abstract Article

Bischoff, M. and Schnabel, R. (2006). A posterior centre establishes and maintains polarity of the Caenorhabditis elegans embryo by a Wnt-dependent relay mechanism. PLoS Biol 4, e396. Abstract Article

Brenner, S. (1974). The genetics of Caenorhabditis elegans. Genetics 77, 71-94. Abstract

Chalfie, M., Horvitz, H.R. and Sulston, J.E. (1981). Mutations that lead to reiterations in the cell lineages of $C$. elegans. Cell 24, 59-69. Abstract

Chalfie, M. and Sulston, J. (1981). Developmental genetics of the mechanosensory neurons of Caenorhabditis elegans. Dev. Biol. 82, 358-370. Abstract

Chalfie, M., Tu, Y., Euskirchen, G., Ward, W.W. and Prasher, D.C. (1994). Green fluorescent protein as a marker for gene expression. Science 263, 802-805. Abstract

Chang, S., Johnston, R.J., Jr. and Hobert, O. (2003). A transcriptional regulatory cascade that controls left/right asymmetry in chemosensory neurons of C. elegans. Genes Dev. 17, 2123-2137. Abstract Article

Cinar, H., Keles, S. and Jin, Y. (2005). Expression profiling of GABAergic motor neurons in Caenorhabditis elegans. Curr. Biol. 15, 340-346. Abstract Article

Cordes, S., Frank, C.A. and Garriga, G. (2006). The C. elegans MELK ortholog PIG-1 regulates cell size asymmetry and daughter cell fate in asymmetric neuroblast divisions. Development 133, 2747-2756. Abstract Article 
Cowing, D. and Kenyon, C. (1996). Correct Hox gene expression established independently of position in Caenorhabditis elegans. Nature 382, 353-356. Abstract Article

de Bono, M. and Maricq, A.V. (2005). Neuronal substrates of complex behaviors in C. elegans. Ann. Rev. Neurosci. 28, 451-501. Abstract Article

Doitsidou, M., Flames, N., Lee, A.C., Boyanov, A. and Hobert, O. (2008). Automated screening for mutants affecting dopaminergic-neuron specification in C. elegans. Nat. Methods 5, 869-872. Abstract Article

Duggan, A., Ma, C. and Chalfie, M. (1998). Regulation of touch receptor differentiation by the Caenorhabditis elegans mec-3 and unc-86 genes. Development 125, 4107-4119. Abstract

Dusenbery, D.B., Sheridan, R.E. and Russell, R.L. (1975). Chemotaxis-defective mutants of the nematode Caenorhabditis elegans. Genetics 80, 297-309. Abstract

Eastman, C., Horvitz, H.R. and Jin, Y. (1999). Coordinated transcriptional regulation of the unc-25 glutamic acid decarboxylase and the unc-47 GABA vesicular transporter by the Caenorhabditis elegans UNC-30 homeodomain protein. J. Neurosci. 19, 6225-6234. Abstract

Efimenko, E., Bubb, K., Mak, H.Y., Holzman, T., Leroux, M.R., Ruvkun, G., Thomas, J.H. and Swoboda, P. (2005). Analysis of $x b x$ genes in C. elegans. Development 132, 1923-1934. Abstract Article

Emmons, S.W. (2005). Male development. WormBook, ed. The C. elegans Research Community, WormBook, doi/10.1895/wormbook.1.33.1, http://www.wormbook.org.

Etchberger, J.F., Flowers, E.B., Poole, R.J., Bashllari, E. and Hobert, O. (2009). Cis-regulatory mechanisms of left/right asymmetric neuron-subtype specification in C. elegans. Development 136, 147-160. Abstract Article

Etchberger, J.F., Lorch, A., Sleumer, M.C., Zapf, R., Jones, S.J., Marra, M.A., Holt, R.A., Moerman, D.G. and Hobert, O. (2007). The molecular signature and cis-regulatory architecture of a C. elegans gustatory neuron. Genes Dev. 21, 1653-1674. Abstract Article

Finney, M. and Ruvkun, G. (1990). The unc-86 gene product couples cell lineage and cell identity in C. elegans. Cell 63, 895-905. Abstract

Finney, M., Ruvkun, G. and Horvitz, H.R. (1988). The C. elegans cell lineage and differentiation gene unc-86 encodes a protein with a homeodomain and extended similarity to transcription factors. Cell 55, 757-769. Abstract

Flames, N. and Hobert, O. (2009). Gene regulatory logic of dopamine neuron differentiation. Nature 458, 885-889. Abstract Article

Flowers, E.B., Poole, R.J., Tursun, B., Bashllari, E., Pe'er, I. and Hobert, O. (2010). The Groucho ortholog UNC-37 interacts with the short Groucho-like protein LSY-22 to control developmental decisions in C. elegans. Development 137, 1799-1805. Abstract Article

Fox, R.M., Von Stetina, S.E., Barlow, S.J., Shaffer, C., Olszewski, K.L., Moore, J.H., Dupuy, D., Vidal, M. and Miller, D.M., 3rd. (2005). A gene expression fingerprint of C. elegans embryonic motor neurons. BMC Genomics 6, 42. Abstract Article

Frank, C.A., Baum, P.D. and Garriga, G. (2003). HLH-14 is a C. elegans achaete-scute protein that promotes neurogenesis through asymmetric cell division. Development 130, 6507-6518. Abstract Article

Frank, C.A., Hawkins, N.C., Guenther, C., Horvitz, H.R. and Garriga, G. (2005). C. elegans HAM-1 positions the cleavage plane and regulates apoptosis in asymmetric neuroblast divisions. Dev. Biol. 284, 301-310. Abstract Article

Greenwald, I. (1989). Cell-cell interactions that specify certain cell fates in C. elegans development. Trends Genet. 5, 237-241. Abstract 
Greenwald, I. (1998). LIN-12/Notch signaling: lessons from worms and flies. Genes Dev. 12, 1751-1762. Abstract

Greenwald, I.S., Sternberg, P.W. and Horvitz, H.R. (1983). The lin-12 locus specifies cell fates in Caenorhabditis elegans. Cell 34, 435-444. Abstract

Grueber, W.B., Jan, L.Y. and Jan, Y.N. (2003). Different levels of the homeodomain protein cut regulate distinct dendrite branching patterns of Drosophila multidendritic neurons. Cell 112, 805-818. Abstract

Guenther, C. and Garriga, G. (1996). Asymmetric distribution of the C. elegans HAM-1 protein in neuroblasts enables daughter cells to adopt distinct fates. Development 122, 3509-3518. Abstract

Guillemot, F. (2007). Spatial and temporal specification of neural fates by transcription factor codes. Development 134, 3771-3780. Abstract Article

Hallam, S., Singer, E., Waring, D. and Jin, Y. (2000). The C. elegans NeuroD homolog cnd-1 functions in multiple aspects of motor neuron fate specification. Development 127, 4239-4252. Abstract

Hedgecock, E.M. and Russell, R.L. (1975). Normal and mutant thermotaxis in the nematode Caenorhabditis elegans. Proc. Natl. Acad. Sci. USA 72, 4061-4065. Abstract

Hemmati-Brivanlou, A. and Melton, D. (1997). Vertebrate neural induction. Annu. Rev. Neurosci. 20, 43-60. Abstract Article

Hobert, O. (2003). Behavioral plasticity in C. elegans: paradigms, circuits, genes. J. Neurobiol. 54, 203-223. Abstract Article

Hobert, O. (2005). Specification of the nervous system. WormBook, ed. The C. elegans Research Community, WormBook, doi/10.1895/wormbook.1.12.1, http://www.wormbook.org.

Hobert, O. (2006). Architecture of a microRNA-controlled gene regulatory network that diversifies neuronal cell fates. Cold Spring Harb. Symp. Quant. Biol. 71, 181-188. Abstract Article

Hobert, O. (2008). Regulatory logic of neuronal diversity: terminal selector genes and selector motifs. Proc. Natl. Acad. Sci. USA 105, 20067-20071. Abstract Article

Hobert, O. (2010). The impact of whole genome sequencing on model system genetics: Get ready for the ride. Genetics, 184, 317-319. Abstract Article

Hobert, O., Carrera, I. and Stefanakis, N. (2010). The molecular and gene regulatory signature of a neuron. Trends Neurosci., Epub ahead of print July 20, 2010. Abstract Article

Hobert, O., D'Alberti, T., Liu, Y. and Ruvkun, G. (1998). Control of neural development and function in a thermoregulatory network by the LIM homeobox gene lin-11. J. Neurosci. 18, 2084-2096. Abstract

Hobert, O., Johnston, R.J., Jr. and Chang, S. (2002). Left-right asymmetry in the nervous system: the Caenorhabditis elegans model. Nat. Rev. Neurosci. 3, 629-640. Abstract Article

Hobert, O., Mori, I., Yamashita, Y., Honda, H., Ohshima, Y., Liu, Y. and Ruvkun, G. (1997). Regulation of interneuron function in the C. elegans thermoregulatory pathway by the ttx-3 LIM homeobox gene. Neuron 19, 345-357. Abstract

Horvitz, H.R., Sternberg, P.W., Greenwald, I.S., Fixsen, W. and Ellis, H.M. (1983). Mutations that affect neural cell lineages and cell fates during the development of the nematode Caenorhabditis elegans. Cold Spring Harb. Symp. Quant. Biol. 48 Pt 2, 453-463. Abstract

Huang, X., Powell-Coffman, J.A. and Jin, Y. (2004). The AHR-1 aryl hydrocarbon receptor and its co-factor the AHA-1 aryl hydrocarbon receptor nuclear translocator specify GABAergic neuron cell fate in $C$. elegans. Development 131, 819-828. Abstract Article 
Hutter, H. and Schnabel, R. (1994). glp-1 and inductions establishing embryonic axes in C. elegans. Development 120, 2051-2064. Abstract

Jarriault, S., Schwab, Y. and Greenwald, I. (2008). A Caenorhabditis elegans model for epithelial-neuronal transdifferentiation. Proc. Natl. Acad. Sci. USA 105, 3790-3795. Abstract Article

Jin, Y., Hoskins, R. and Horvitz, H.R. (1994). Control of type-D GABAergic neuron differentiation by C. elegans UNC-30 homeodomain protein. Nature 372, 780-783. Abstract Article

Johnston, R.J. and Hobert, O. (2003). A microRNA controlling left/right neuronal asymmetry in Caenorhabditis elegans. Nature 426, 845-849. Abstract Article

Johnston, R.J., Jr., Chang, S., Etchberger, J.F., Ortiz, C.O. and Hobert, O. (2005). MicroRNAs acting in a double-negative feedback loop to control a neuronal cell fate decision. Proc. Natl. Acad. Sci. USA 102, 12449-12454. Abstract Article

Jorgensen, E.M. and Mango, S.E. (2002). The art and design of genetic screens: Caenorhabditis elegans. Nat. Rev. Genet. 3, 356-369. Abstract Article

Kaletta, T., Schnabel, H. and Schnabel, R. (1997). Binary specification of the embryonic lineage in Caenorhabditis elegans. Nature 390, 294-298. Abstract Article

Kim, K., Kim, R. and Sengupta, P. (2010). The HMX/NKX homeodomain protein MLS-2 specifies the identity of the AWC sensory neuron type via regulation of the ceh-36 Otx gene in C. elegans. Development 137, 963-974. Abstract Article

Kim, K. and Li, C. (2004). Expression and regulation of an FMRFamide-related neuropeptide gene family in Caenorhabditis elegans. J. Comp. Neurol. 475, 540-550. Abstract Article

Labouesse, M., Sookhareea, S. and Horvitz, H.R. (1994). The Caenorhabditis elegans gene lin-26 is required to specify the fates of hypodermal cells and encodes a presumptive zinc-finger transcription factor. Development 120 , 2359-2368. Abstract

Lanjuin, A. and Sengupta, P. (2004). Specification of chemosensory neuron subtype identities in Caenorhabditis elegans. Curr. Opin. Neurobiol. 14, 22-30. Abstract Article

Lanjuin, A., VanHoven, M.K., Bargmann, C.I., Thompson, J.K. and Sengupta, P. (2003). Otx/otd Homeobox Genes Specify Distinct Sensory Neuron Identities in C. elegans. Dev. Cell 5, 621-633. Abstract

Laurencon, A., Dubruille, R., Efimenko, E., Grenier, G., Bissett, R., Cortier, E., Rolland, V., Swoboda, P. and Durand, B. (2007). Identification of novel regulatory factor X (RFX) target genes by comparative genomics in Drosophila species. Genome Biol. 8, R195. Abstract Article

Lesch, B.J., Gehrke, A.R., Bulyk, M.L. and Bargmann, C.I. (2009). Transcriptional regulation and stabilization of left-right neuronal identity in C. elegans. Genes Dev. 23, 345-358. Abstract Article

Lin, R., Hill, R.J. and Priess, J.R. (1998). POP-1 and anterior-posterior fate decisions in C. elegans embryos. Cell 92, 229-239. Abstract

Lints, R., Jia, L., Kim, K., Li, C. and Emmons, S.W. (2004). Axial patterning of C. elegans male sensilla identities by selector genes. Dev. Biol. 269, 137-151. Abstract Article

Melkman, T. and Sengupta, P. (2005). Regulation of chemosensory and GABAergic motor neuron development by the C. elegans Aristaless/Arx homolog alr-1. Development 132, 1935-1949. Abstract Article

Miller, D.M., 3rd and Niemeyer, C.J. (1995). Expression of the unc-4 homeoprotein in Caenorhabditis elegans motor neurons specifies presynaptic input. Development 121, 2877-2886. Abstract 
Miller, D.M., Shen, M.M., Shamu, C.E., Burglin, T.R., Ruvkun, G., Dubois, M.L., Ghee, M. and Wilson, L. (1992). C. elegans unc-4 gene encodes a homeodomain protein that determines the pattern of synaptic input to specific motor neurons. Nature 355, 841-845. Abstract Article

Mizumoto, K. and Sawa, H. (2007). Two betas or not two betas: regulation of asymmetric division by beta-catenin. Trends Cell Biol. 17, 465-473. Abstract Article

Modolell, J. (1997). Patterning of the adult peripheral nervous system of Drosophila. Perspect. Dev. Neurobiol. 4, 285-296. Abstract

Murray, J.I., Bao, Z., Boyle, T.J., Boeck, M.E., Mericle, B.L., Nicholas, T.J., Zhao, Z., Sandel, M.J. and Waterston, R.H. (2008). Automated analysis of embryonic gene expression with cellular resolution in C. elegans. Nat. Methods 5, 703-9. Abstract Article

Palmer, A.R. (1996). From symmetry to asymmetry: phylogenetic patterns of asymmetry variation in animals and their evolutionary significance. Proc. Natl. Acad. Sci. USA 93, 14279-14286. Abstract

Phillips, B.T., Kidd, A.R., 3rd, King, R., Hardin, J. and Kimble, J. (2007). Reciprocal asymmetry of SYS-1/beta-catenin and POP-1/TCF controls asymmetric divisions in Caenorhabditis elegans. Proc. Natl. Acad. Sci. USA 104, 3231-3236. Abstract Article

Phillips, B.T. and Kimble, J. (2009). A new look at TCF and beta-catenin through the lens of a divergent C. elegans Wnt pathway. Dev. Cell 17, 27-34. Abstract Article

Pierce-Shimomura, J.T., Faumont, S., Gaston, M.R., Pearson, B.J. and Lockery, S.R. (2001). The homeobox gene lim-6 is required for distinct chemosensory representations in C. elegans. Nature 410, 694-698. Abstract Article

Poole, R.J. and Hobert, O. (2006). Early embryonic programming of neuronal left/right asymmetry in C. elegans. Curr. Biol. 16, 2279-2292. Abstract Article

Prasad, B.C., Ye, B., Zackhary, R., Schrader, K., Seydoux, G. and Reed, R.R. (1998). unc-3, a gene required for axonal guidance in Caenorhabditis elegans, encodes a member of the $\mathrm{O} / \mathrm{E}$ family of transcription factors. Development 125, 1561-1568. Abstract

Pujol, N., Torregrossa, P., Ewbank, J.J. and Brunet, J.F. (2000). The homeodomain protein CePHOX2/CEH-17 controls antero-posterior axonal growth in C. elegans. Development 127, 3361-3371. Abstract

Remy, J.J. and Hobert, O. (2005). An interneuronal chemoreceptor required for olfactory imprinting in C. elegans. Science 309, 787-790. Abstract Article

Ruvinsky, I., Ohler, U., Burge, C.B. and Ruvkun, G. (2007). Detection of broadly expressed neuronal genes in $C$. elegans. Dev. Biol. 302, 617-626. Abstract Article

Sagasti, A., Hisamoto, N., Hyodo, J., Tanaka-Hino, M., Matsumoto, K. and Bargmann, C.I. (2001). The CaMKII UNC-43 activates the MAPKKK NSY-1 to execute a lateral signaling decision required for asymmetric olfactory neuron fates. Cell 105, 221-232. Abstract

Salser, S.J. and Kenyon, C. (1992). Activation of a C. elegans Antennapedia homologue in migrating cells controls their direction of migration. Nature 355, 255-258. Abstract Article

Salser, S.J. and Kenyon, C. (1994). Patterning C. elegans: homeotic cluster genes, cell fates and cell migrations. Trends Genet. 10, 159-164. Abstract

Sarafi-Reinach, T.R., Melkman, T., Hobert, O. and Sengupta, P. (2001). The lin-11 LIM homeobox gene specifies olfactory and chemosensory neuron fates in C. elegans. Development 128, 3269-3281. Abstract

Sarafi-Reinach, T.R. and Sengupta, P. (2000). The forkhead domain gene unc-130 generates chemosensory neuron diversity in C. elegans. Genes Dev. 14, 2472-2485. Abstract 
Sarin, S., Antonio, C., Tursun, B. and Hobert, O. (2009). The C. elegans Tailless/TLX transcription factor nhr-67 controls neuronal identity and left/right asymmetric fate diversification. Development, 136, 2933-2944. Abstract Article

Schmid, C., Schwarz, V. and Hutter, H. (2006). AST-1, a novel ETS-box transcription factor, controls axon guidance and pharynx development in C. elegans. Dev. Biol. 293, 403-413. Abstract Article

Sengupta, P., Colbert, H.A. and Bargmann, C.I. (1994). The C. elegans gene odr-7 encodes an olfactory-specific member of the nuclear receptor superfamily. Cell 79, 971-980. Abstract

Shaham, S. (2006). Glia-neuron interactions in the nervous system of Caenorhabditis elegans. Curr. Opin. Neurobiol. 16, 522-528. Abstract Article

Shi, Y. and Mello, C. (1998). A CBP/p300 homolog specifies multiple differentiation pathways in Caenorhabditis elegans. Genes Dev. 12, 943-955. Abstract

Sulston, J.E. (1983). Neuronal cell lineages in the nematode Caenorhabditis elegans. Cold Spring Harb. Symp. Quant. Biol. 48, 443-452. Abstract

Sulston, J.E., Albertson, D.G. and Thomson, J.N. (1980). The Caenorhabditis elegans male: postembryonic development of nongonadal structures. Dev. Biol. 78, 542-576. Abstract

Sulston, J.E. and Horvitz, H.R. (1977). Post-embryonic cell lineages of the nematode, Caenorhabditis elegans. Dev. Biol. 56, 110-156. Abstract

Sulston, J.E., Schierenberg, E., White, J.G. and Thomson, J.N. (1983). The embryonic cell lineage of the nematode Caenorhabditis elegans. Dev. Biol. 100, 64-119. Abstract

Swoboda, P., Adler, H.T. and Thomas, J.H. (2000). The RFX-type transcription factor DAF-19 regulates sensory neuron cilium formation in C. elegans. Mol. Cell 5, 411-421. Abstract

Troemel, E.R., Sagasti, A. and Bargmann, C.I. (1999). Lateral signaling mediated by axon contact and calcium entry regulates asymmetric odorant receptor expression in C. elegans. Cell 99, 387-398. Abstract

Tsalik, E.L. and Hobert, O. (2003). Functional mapping of neurons that control locomotory behavior in Caenorhabditis elegans. J. Neurobiol. 56, 178-197. Abstract Article

Tsalik, E.L., Niacaris, T., Wenick, A.S., Pau, K., Avery, L. and Hobert, O. (2003). LIM homeobox gene-dependent expression of biogenic amine receptors in restricted regions of the C. elegans nervous system. Dev. Biol. 263, 81-102. Abstract

Uchida, O., Nakano, H., Koga, M. and Ohshima, Y. (2003). The C. elegans che-1 gene encodes a zinc finger transcription factor required for specification of the ASE chemosensory neurons. Development 130, 1215-1224. Abstract

Von Stetina, S.E., Fox, R.M., Watkins, K.L., Starich, T.A., Shaw, J.E. and Miller, D.M., 3rd. (2007). UNC-4 represses CEH-12/HB9 to specify synaptic inputs to VA motor neurons in C. elegans. Genes Dev. 21, 332-346. Abstract Article

Von Stetina, S.E., Treinin, M. and Miller, D.M. (2006). The motor circuit. Int. Rev. Neurobiol. 69, 125-167. Abstract Article

Wacker, I., Schwarz, V., Hedgecock, E.M. and Hutter, H. (2003). zag-1, a Zn-finger homeodomain transcription factor controlling neuronal differentiation and axon outgrowth in C. elegans. Development 130, 3795-3805. Abstract

Wadsworth, W.G., Bhatt, H. and Hedgecock, E.M. (1996). Neuroglia and pioneer neurons express UNC-6 to provide global and local netrin cues for guiding migrations in C. elegans. Neuron 16, 35-46. Abstract 
Way, J.C. and Chalfie, M. (1988). mec-3, a homeobox-containing gene that specifies differentiation of the touch receptor neurons in C. elegans. Cell 54, 5-16. Abstract

Wenick, A.S. and Hobert, O. (2004). Genomic cis-regulatory architecture and trans-acting regulators of a single interneuron-specific gene battery in C. elegans. Dev. Cell 6, 757-770. Abstract Article

Wes, P.D. and Bargmann, C.I. (2001). C. elegans odour discrimination requires asymmetric diversity in olfactory neurons. Nature 410, 698-701. Abstract Article

White, J.G., Southgate, E., Thomson, J.N. and Brenner, S. (1986). The structure of the nervous system of the nematode Caenorhabditis elegans. Philosophical Transactions of the Royal Society of London B. Biological Sciences 314, 1-340.

Winnier, A.R., Meir, J.Y., Ross, J.M., Tavernarakis, N., Driscoll, M., Ishihara, T., Katsura, I. and Miller, D.M., 3rd. (1999). UNC-4/UNC-37-dependent repression of motor neuron-specific genes controls synaptic choice in Caenorhabditis elegans. Genes Dev. 13, 2774-2786. Abstract

Wittmann, C., Bossinger, O., Goldstein, B., Fleischmann, M., Kohler, R., Brunschwig, K., Tobler, H. and Muller, F. (1997). The expression of the C. elegans labial-like Hox gene ceh-13 during early embryogenesis relies on cell fate and on anteroposterior cell polarity. Development 124, 4193-4200. Abstract

Wrischnik, L.A. and Kenyon, C.J. (1997). The role of lin-22, a hairy/enhancer of split homolog, in patterning the peripheral nervous system of C. elegans. Development 124, 2875-2888. Abstract

Xue, D., Finney, M., Ruvkun, G. and Chalfie, M. (1992). Regulation of the mec-3 gene by the C. elegans homeoproteins UNC-86 and MEC-3. Embo J. 11, 4969-4979. Abstract

Xue, D., Tu, Y. and Chalfie, M. (1993). Cooperative interactions between the Caenorhabditis elegans homeoproteins UNC-86 and MEC-3. Science 261, 1324-1328. Abstract

Yoshimura, S., Murray, J.I., Lu, Y., Waterston, R.H. and Shaham, S. (2008). $m l s-2$ and vab-3 control glia development, hlh-17/Olig expression and glia-dependent neurite extension in C. elegans. Development 135, 2263-2275. Abstract Article

Yu, S., Avery, L., Baude, E. and Garbers, D.L. (1997). Guanylyl cyclase expression in specific sensory neurons: a new family of chemosensory receptors. Proc. Natl. Acad. Sci. USA 94, 3384-3387. Abstract

Zhang, Y., Ma, C., Delohery, T., Nasipak, B., Foat, B.C., Bounoutas, A., Bussemaker, H.J., Kim, S.K. and Chalfie, M. (2002). Identification of genes expressed in C. elegans touch receptor neurons. Nature 418, 331-335. Abstract Article

Zhao, C. and Emmons, S.W. (1995). A transcription factor controlling development of peripheral sense organs in $C$. elegans. Nature 373, 74-78. Abstract Article

Zhou, H.M. and Walthall, W.W. (1998). UNC-55, an orphan nuclear hormone receptor, orchestrates synaptic specificity among two classes of motor neurons in Caenorhabditis elegans. J. Neurosci. 18, 10438-10444. Abstract

All WormBook content, except where otherwise noted, is licensed under a Creative Commons Attribution License. 